NBER WORKING PAPER SERIES

\title{
FINANCIAL INNOVATION, MARKET PARTICIPATION \\ AND ASSET PRICES
}

\author{
Laurent Calvet \\ Martín Gonzalez-Eiras \\ Paolo Sodini
}

Working Paper 9840

http://www.nber.org/papers/w9840

\author{
NATIONAL BUREAU OF ECONOMIC RESEARCH \\ 1050 Massachusetts Avenue \\ Cambridge, MA 02138 \\ July 2003
}

Earlier versions of this paper appear in the Ph.D. dissertations of M. Gonzalez-Eiras and P. Sodini. We received helpful comments from D. Acemoglu, F. Alvarez, S. Basak, O. Blanchard, R. Caballero, J. Campbell, J. Detemple, P. Diamond, A. Fisher, R. Giammarino, G. Mankiw, E. Maskin, M. Pagano, T. Persson, S. Ross, R. Uppal, D. Vayanos, T. Vuolteenaho, J. Wang, and seminar participants at Boston University, CEU, ESSEC, Gerzensee, Harvard, INSEAD, the London School of Economics, MIT, NYU, Salerno, San Andrés, the Stockholm School of Economics, UBC, the University of Amsterdam, the University of Cyprus, UTDT, the University of Trieste, the Rolf Mantel Memorial Conference, the 2000 LACEA Meeting, the 2001 European Summer Meeting of the Econometric Society and the 2002 NBER Meeting on Economic Fluctuations and Growth. The paper also benefited from excellent research assistance by Charles P. Cohen. The views expressed herein are those of the authors and not necessarily those of the National Bureau of Economic Research

(C)2003 by Laurent Calvet, Martín Gonzalez-Eiras, and Paolo Sodini. All rights reserved. Short sections of text not to exceed two paragraphs, may be quoted without explicit permission provided that full credit including (C) notice, is given to the source. 
Financial Innovation, Market Participation and Asset Prices

Laurent Calvet, Martín Gonzalez-Eiras, and Paolo Sodini

NBER Working Paper No. 9840

July 2003

JEL No. D52, E44, G12

\begin{abstract}
This paper investigates the pricing effects of financial innovation in an economy with endogenous participation and heterogeneous income risks. The introduction of non-redundant assets endogenously modifies the participation set, reduces the covariance between dividends and participants' consumption and thus leads to lower risk premia. In multisector economies, financial innovation spreads across markets through the diversified portfolio of new entrants, and has rich effects on the cross-section of expected returns. The price changes can also lead some investors to leave the markets and give rise to non-degenerate forms of participation turnover. The model is consistent with several features of financial markets over the past few decades: substantial innovation; higher participation; significant turnover in investor composition; improved risk management practices; a slight increase in interest rates; and a reduction in risk premia.
\end{abstract}

\author{
Laurent Calvet \\ Department of Economics \\ Harvard University \\ Littauer Center \\ Cambridge, MA 02138 \\ and NBER \\ lcalvet@aya.yale.edu \\ Paolo Sodoni \\ Department of Finance \\ Stockholm School of Economics \\ Sveavägen 65 \\ Box 6501 \\ SE-113 83 Stockholm \\ Sweden \\ paolo.sodini@hhs.se \\ Martín Gonzalez-Eiras \\ Departamento de Economía \\ Universidad de San Andrés \\ Vito Dumas 284 (1644)- Victoria \\ Buenos Aires, Argentina \\ mge@udesa.edu.ar
}




\section{Introduction}

The introduction of a vast array of non-redundant securities has transformed financial markets over the past few decades. Derivative contracts now allow firms to routinely manage their exposure to commodity and financial prices. ${ }^{1}$ New insurance and financial products provide additional diversification opportunities to individual investors. Initial public offerings have enabled entrepreneurs to diversify some of their wealth away from the companies in which they had managerial interests. ${ }^{2}$ Financial theory suggests that these innovations might have profound implications for portfolio choice, asset pricing and the cross-sectional allocation of risk. ${ }^{3}$ For instance, new instruments allow agents to reduce their exposure to idiosyncratic or background shocks, which increases the demand for stocks and leads to a lower market premium (e.g. Kihlstrom, Romer and Williams, 1981; Nachman, 1982; Campbell and Viceira, 2002).

This paper shows that new mechanisms arise when participation is endogenized in an economy with heterogeneous income risks. ${ }^{4}$ The introduction of new securities changes the participation set, decreases the covariance between dividends and participants' consumption, and thus amplifies the reduction in the market premium. In multifactor economies, financial innovation also spreads across markets through the diversified portfolio choices of new entrants and has rich effects on the cross-section of expected returns. The price changes can also lead some investors to leave financial markets. Innovation then induces the simultaneous entry and exit of investors, giving rise to non-degenerate forms of participation turnover. ${ }^{5}$

Our approach builds on the existence of fixed costs to participate in financial markets. Corporate hedging requires the employment of experts able to effectively reduce the firm's risk exposure using existing financial assets. Investors have to sustain learning efforts and expenses related to the opening and maintenance of accounts with an exchange or a brokerage firm. Statutory and government reg-

\footnotetext{
${ }^{1}$ See for instance Ross (1976).

${ }^{2}$ Shiller (2003) provides a recent review of these developments.

${ }^{3}$ Theoretical investigations of financial innovation include Allen and Gale (1994a, b), Calvet (2001), Cass and Citanna (1998), Detemple and Selden (1991), Duffie and Jackson (1989), Grossman (1989), Huang and Wang (1997), and Stein (1987). See Duffie and Rahi (1995) for a review.

${ }^{4}$ While the discussion focuses on the effect of an increase in spanning, the paper also analyzes the consequences of a reduction in transactions costs.

${ }^{5}$ Hurst, Luoh and Stafford (1998) and Vissing-Jørgensen (2002) report substantial rates of entry and exit in US stockownership.
} 
ulations often create costly barriers to the participation of institutional investors in some markets.

We introduce a two-period economy with incomplete markets and endogenous participation. Agents can borrow or lend freely, but have to pay a fixed entry cost to invest in risky assets. They receive heterogeneous random incomes determined by a finite number of macroeconomic risk factors. Security prices and the participation structure are jointly determined in equilibrium. The model is computationally tractable and leads to a closed-form system of equilibrium equations in the CARA-normal case. As mentioned earlier, three new mechanisms arise in this economy.

First, the introduction of non-redundant instruments encourages more investors to participate in financial markets for hedging and diversification purposes. Under plausible conditions on the cross-sectional distribution of risk, the new entrants reduce the covariance between stock returns and the mean consumption of participants, leading to a lower market premium. The model thus illustrates the connection between the cross-sectional distribution of risk and the price impact of new assets. It is also consistent with features that have characterized financial markets in the past few decades: substantial financial innovation, a sharp increase in investor participation, improvements in risk-management practices, a slight increase of real interest rates, and a reduction in the risk premium. ${ }^{6}$

Second, participation plays an important role in spreading the effects of innovation across markets. When a common factor becomes tradable, some agents decide to pay the entry fee and trade the new contract in order to manage their risk exposure. The new participants achieve optimal diversification by trading other assets, which modifies the risk premia even in sectors uncorrelated to the new contract. Furthermore, the entrants tend to have a stronger impact on the average exposure to the factor than on other sectors of the economy. As a result, price changes are more pronounced for assets correlated with the new contract. Financial innovation thus differentially affects distinct sectors of the economy and has a rich impact on the cross-section of expected returns.

Third, the price changes induced by financial innovation can give rise to nondegenerate forms of participation turnover. For instance, the introduction of a new asset leads some agents to enter financial markets to manage their income

\footnotetext{
${ }^{6}$ The decrease in the risk premium is reported in Blanchard (1993), Campbell and Shiller (2003), Cochrane (1997) and Fama and French (2002). Similarly, Barro and Sala-i-Martin (1990) and Honohan (2000) document a slight increase in real interest rates over the past three decades.
} 
risk. Other agents, however, are adversely affected by the induced changes in risk premia and may find it optimal to stop trading. Innovation can therefore induce simultaneous entry and exit. The paper thus helps relate participation turnover with the cross-sectional distribution of risk in multisector economies.

Section 2 introduces a tractable asset pricing model with endogenous entry. Section 3 demonstrates the pricing and participation effects of financial innovation in a one-factor model of risk exposure. Multiple factors are considered in Section 4. Simple simulations suggest that financial innovation substantially reduces the equity premium, differentially spreads across security markets, and either increases or decreases the interest rate. All proofs are given in the Appendix.

\subsection{Review of Previous Literature}

This paper builds on two strands of the asset pricing literature that have essentially been developed separately. First, researchers have examined how limited investor participation affects the prices of a fixed set of securities. Second, the price impact of financial innovation has been examined both empirically and theoretically without consideration of participation. The novelty of this paper is to combine these two lines of research in a simple and tractable framework.

Empirical research on stockmarket participation was pioneered by Blume, Crockett and Friend (1974), Blume and Friend (1978), and King and Leape (1984). Mankiw and Zeldes (1991) report that only 28\% of households owned stocks in 1984 , and that $47 \%$ of households with liquid assets in excess of $\$ 100,000$ held any equity. ${ }^{7}$ The fraction of households owning stocks increases with income and education, implying that there could be fixed information costs to participate in financial markets. Stockholder consumption is also more highly correlated with the market portfolio than aggregate consumption. The distinction between stockholders and non-stockholders therefore helps explain the equity premium puzzle. The empirical validity of this mechanism is further confirmed by Vissing-Jørgensen (1997). Poterba and Samwick (1995) and Vissing-Jørgensen (1997) also document the sharp increase of stock market participation in the United States since 1945.

These empirical findings have prompted the development of theoretical models that restrict participation exogenously. Saito (1995) and Basak and Cuoco (1998) thus consider two-asset exchange economies in which the risky security spans individual income. At low participation levels, a small number of agents bears in

\footnotetext{
${ }^{7}$ The structure of stockownership is further analyzed by Blume and Zeldes (1993) and Bertaut and Haliassos (1995).
} 
equilibrium the aggregate risk of the entire population. As a result, the market premium is high and matches the historical average under reasonable levels of risk aversion. Heaton and Lucas (1999) extend the analysis by considering heterogeneous incomes with a common nonmarketable factor. In contrast to this earlier work, we consider multiple assets and factors, and endogenize the participation structure by considering fixed costs to trading in financial markets. The entry-cost approach has been widely used in finance to analyze issues such as portfolio choice (Campbell, Cocco, Gomes and Maenhout, 2001), volatility (Pagano, 1989; Allen and Gale, 1994b; Orosel, 1998), futures risk premia (Hirshleifer, 1988), market size (Allen and Gale, 1990; Pagano, 1993), and the effect of social security reform on capital accumulation (Abel, 2001). We use this setup to analyze how financial innovation affects investor participation and asset prices.

The paper is also related to the literature that examines the price impact of financial innovation without consideration of participation. Conrad (1989) and Detemple and Jorion (1990) find empirically that the introduction of new batches of options had a substantial price impact between 1973 and 1986. The effect is stronger for underlying stocks, but can also be observed for an industry index that excludes the optioned stock as well as for the market index. Similar empirical evidence is available for other countries and derivative markets (e.g. Jochum and Kodres, 1998).

A rich theoretical literature has also explored the impact of innovation, and three results are most directly related to our model. First, the introduction of a new security permits agents to better share risk and thus weakens the precautionary supply of savings. This leads to a higher equilibrium interest rate, which reduces the price of all assets in fixed-participation exchange economies (Weil, 1992; Elul, 1997). ${ }^{8}$ In contrast, we will show that price changes induced by innovation can cause some investors to exit the market. Lower participation then encourages precautionary savings and reduces the equilibrium interest rate in some economies.

Second, financial innovation does not affect risk-pricing in standard meanvariance settings with fixed participation (Oh, 1996). Specifically in quadratic or CARA-normal economies, the price of any risky security relative to the bond is unaffected by changes in the span. For this reason, researchers have made little use of mean-variance models to analyze the pricing implications of innovation. ${ }^{9}$ We

\footnotetext{
${ }^{8}$ See Angeletos and Calvet (2000) for the analysis of production economies.

${ }^{9}$ Detemple and Selden (1991) is a notable exception.
} 
will show that CARA-normal economies can be quite useful when the participation structure is endogenized. New assets induce the entry of new investors, which lowers the systematic consumption risk of participants and therefore increases the price of preexisting securities.

Third, financial innovation allows agents to reduce their exposure to idiosyncratic or background shocks, which stimulates the demand for stocks (e.g. Kihlstrom, Romer and Williams, 1981; Nachman, 1982; Gollier, 2001; Campbell and Viceira, 2002). As a result, equilibrium risk premia tend to be lower after the introduction of new assets. In our model, however, agents have CARA utilities and reductions in background risk do not affect the demand for risky assets. Changes in the systematic consumption risk of participants are the only contributing factors to lower premia in our setup, which will greatly simplify the interpretation of the results. We anticipate that our mechanism complements and amplifies the background risk channel when individual utilities are isoelastic or more generally exhibit decreasing absolute risk aversion.

\section{A Model of Endogenous Market Participation}

We examine an exchange economy with two periods $(t=0,1)$ and a single perishable good. The economy is deterministic at date $t=0$ and stochastic at $t=1$. During her life, each agent $h$ receives an exogenous random endowment $e^{h}=\left(e_{0}^{h}, \tilde{e}^{h}\right)$, which corresponds for instance to a stochastic labor income. Her preference over consumption streams $\left(c_{0}^{h}, \widetilde{c}^{h}\right)$ is represented by a utility function $U^{h}\left(c_{0}^{h}, \widetilde{c}^{h}\right)$. We thus adopt the two-period setup that has widely been used in the financial innovation literature for its tractability (e.g. Allen and Gale 1994 $a, b)$. We anticipate that our model provides useful insights on the properties of multiperiod economies with permanent shocks. ${ }^{10}$

This paper places no restriction on the set of agents $H$, which can be finite or infinite. To provide a uniform treatment, we endow the space $H$ with a measure $\mu$ that satisfies $\mu(H)=1$. This is equivalent to viewing each element of $H$ as a type, and the measure $\mu$ as a probability distribution over all possible types.

At date $t=0$, agents can exchange a finite number of real securities, whose

\footnotetext{
${ }^{10}$ A large body of research shows that transitory shocks can be easily self-insured while persistent shocks have profound pricing and welfare implications in dynamic economies with incomplete markets (e.g. Bewley, 1977; Telmer, 1993; Constantinides and Duffie, 1996; Storesletten, Telmer and Yaron, 1996; Levine and Zame, 2002). The extension of our framework to the dynamic case, for instance following Calvet (2001), is a promising direction for future research.
} 
initial prices and final payoffs are denominated in units of the consumption good. The financial structure is exogenous and contains two types of assets. First, agents can trade a riskless asset costing $\pi_{0}=1 / R$ in date $t=0$ and delivering one unit of the good with certainty at date $t=1$. Note that $R$ is the gross interest rate. Second, there also exist $J$ risky assets $(j=1, \ldots J)$ with price $\pi_{j}$ and random payoff $\tilde{a}_{j}$. We assume for simplicity that all assets are in zero net supply. ${ }^{11}$ Investors can freely operate in the bond market but have to pay a fixed entry cost $\kappa$ in order to invest in one or more risky assets. This assumption is consistent with complementarities of learning in trading activities, and the results of the paper easily generalize to more flexible specifications of the entry cost. Investors are price-takers both in their entry and portfolio decisions, and there are no constraints on short sales. Let $\pi$ denote the vector of risky asset prices, and $\theta^{h}$ the vector of risky assets bought (or sold) by investor $h$. We also consider the dummy variable $1_{\left\{\theta^{h} \neq 0\right\}}$ equal to 1 if $\theta^{h} \neq 0$, and equal to 0 otherwise. The agent is subject to the budget constraints

$$
\begin{aligned}
& c_{0}^{h}+\theta_{0}^{h} / R+\pi \cdot \theta^{h}+\kappa 1_{\left\{\theta^{h} \neq 0\right\}}=e_{0}^{h}, \\
& \tilde{c}^{h}=\tilde{e}^{h}+\theta_{0}^{h}+\tilde{a} \cdot \theta^{h} .
\end{aligned}
$$

These equations are standard, except for the presence of the entry cost in the resource constraint at date 0 . We determine the optimal choice $\left(c_{0}^{h}, \tilde{c}^{h}, \theta_{0}^{h}, \theta^{h}\right)$ by calculating the consumption-portfolio decision under entry and non-entry. Comparing the resulting utility levels yields the optimal participation decision.

Let $e_{0}=\int_{H} e_{0}^{h} d \mu(h)$ and $\tilde{e}=\int_{H} \tilde{e}^{h} d \mu(h)$ denote the average income of the entire population.

Definition (Equilibrium). A general equilibrium with endogenous participation (GEEP) consists of an interest rate $R$, a price vector $\pi$, and a collection of optimal plans $\left(c_{0}^{h}, \tilde{c}^{h}, \theta_{0}^{h}, \theta^{h}\right)_{h \in H}$ such that:

(a) The good market clears in every state: $\int_{H}\left(c_{0}^{h}+\kappa 1_{\left\{\theta^{h} \neq 0\right\}}\right) d \mu(h)=e_{0}$, and

$$
\int_{H} \tilde{c}^{h}(\omega) d \mu(h)=\tilde{e}(\omega) \text { for all } \omega \in \Omega
$$

(b) The asset markets clear: $\int_{H} \theta_{j}^{h} d \mu(h)=0$ for all $j \in\{0, \ldots, J\}$.

In the absence of entry fee $(\kappa=0)$, the definition coincides with the traditional concept of general equilibrium under incomplete markets (GEI). When participa-

\footnotetext{
${ }^{11}$ A positive supply of assets could be considered by redefining individual endowment as the sum of a labor income and an exogenous portfolio of securities. This is a standard convention in asset pricing theory, as discussed for instance in Magill and Quinzii (1996, ch. 3).
} 
tion is costly, a GEEP differs from a GEI through two different channels. First, agents endogenously decide whether to pay the entry fee in order to trade risky assets. Second, trading activities use some of society's resources and crowd out private consumption, as seen in the market clearing condition at date $t=0$. This phenomenon, which we call the displacement effect, probably plays a minor role in actual economies. Extensions of our model could transfer a fraction of trading fees to some consumers (such as exchange owners), or seek to provide a more detailed description of the financial industry.

The existence of equilibrium is proven in Appendix A. As in the GEI case, equilibrium allocations are usually Pareto inefficient because missing markets induce incomplete risk-sharing. With two periods and a single good, however, GEI allocations are known to satisfy a limited or constrained form of efficiency. No social planner can improve the utility of all agents when income transfers are constrained to belong to the asset span. This limited form of efficiency easily generalizes to our setting when the planner pays the entry fee required to use the risky asset.

Definitions (Constrained Efficiency). An allocation $\left(c_{0}^{h}, \tilde{c}^{h}\right)_{h \in H}$ is feasible if: (a) For all $h$, there exists $\left(\theta_{0}^{h}, \theta^{h}\right) \in \mathbb{R} \times \mathbb{R}^{J}$ such that $\tilde{c}^{h}=\tilde{e}^{h}+\theta_{0}^{h}+\tilde{a} \cdot \theta^{h}$. (b) $\int_{H}\left(c_{0}^{h}+\kappa 1_{\left\{\theta^{h} \neq 0\right\}}\right) d \mu(h)=e_{0}$, and $\int_{H} \tilde{c}^{h}(\omega) d \mu(h)=\tilde{e}(\omega)$ for all $\omega \in \Omega$. A feasible allocation is called constrained Pareto-efficient if no other feasible allocation makes all agents strictly better off.

Appendix A shows that a GEEP allocation is constrained Pareto-efficient. As a result, the introduction of a non redundant asset cannot make all agents worse off.

In order to analyze the effect of financial innovation on participation and prices, we now specialize to a tractable class of CARA-normal economies. Investors have identical utility of the Epstein-Zin type:

$$
U\left(c_{0}, \widetilde{c}\right)=-e^{-\chi c_{0}}-\beta\left[\mathbb{E} e^{-\gamma \widetilde{c}}\right]^{\chi / \gamma},
$$

where $\gamma$ and $\chi$ are positive coefficients. The agent maximizes $-e^{-\chi c_{0}}-\beta e^{-\chi c_{1}}$ when she reallocates through time a deterministic income flow. On the other hand, atemporal risky choices only depend on $\mathbb{E} e^{-\gamma \widetilde{c}}$. When future consumption is normally distributed, we can rewrite the utility as $-e^{-\chi c_{0}}-\beta e^{-\chi[\mathbb{E} \widetilde{c}-\gamma \operatorname{Var}(\widetilde{c}) / 2]}$. The specification reduces to standard expected utility when $\chi=\gamma$. 
Individual endowments and the payoffs of risky assets are jointly normal. The securities generate a linear subspace in the set $L^{2}(\Omega)$ of square-integrable random variables. We assume without loss of generality that risky assets are centered and mutually independent: $\left(\tilde{a}_{1}, . ., \tilde{a}_{J}\right) \sim \mathcal{N}(0, I)$. Let $A$ denote the span of the risky assets, and $A^{\perp}$ the subspace orthogonal to all securities (including the bond). Projections play an important role in the discussion, and $\tilde{x}^{V}$ conveniently denotes the projection of a random variable $\tilde{x}$ on a subspace $V$.

\subsection{Individual Entry Decision}

We solve the decision problem of a given trader $h$ by calculating the consumption - portfolio choice under entry and non-entry. Consider the security $\tilde{m}^{A} \equiv$ $-(R / \gamma) \sum_{j=1}^{J} \pi_{j} \tilde{a}_{j}$, which is determined by risk aversion and market prices. We can easily show:

Proposition 1 (Optimal Portfolio of Participant). A market participant buys

$$
\theta_{0}^{h, p}=\frac{R}{1+R}\left\{e_{0}^{h}-\mathbb{E} \tilde{e}^{h}-\kappa-\pi \cdot \theta^{h, p}+\frac{\ln (R \beta)}{\chi}+\frac{\gamma}{2}\left[\operatorname{Var}\left(\tilde{e}^{h A^{\perp}}\right)+\operatorname{Var}\left(\tilde{m}^{A}\right)\right]\right\}
$$

units of the bond, and $\theta_{j}^{h, p}=-\operatorname{Cov}\left(\tilde{a}_{j}, \tilde{e}^{h}\right)-R \pi_{j} / \gamma$ units of risky asset $j$. Consumption is

$$
\widetilde{c}^{h, p}=\mathbb{E} \tilde{e}^{h}+\theta_{0}^{h, p}+\tilde{m}^{A}+\tilde{e}^{h A^{\perp}}
$$

in the second period.

We infer from (2.1) that the investor exchanges the marketable component $\tilde{e}^{\text {hA }}$ of her income risk for the tradable portfolio $\tilde{m}^{A}$, which provides the optimal mix of risk and return. Because markets are incomplete, she is also constrained to bear the undiversifiable income risk $\tilde{e}^{h A^{\perp}}$.

Investment in the riskless asset is the sum of two components, which correspond to intertemporal smoothing and the precautionary motive. First, the agent uses the riskless asset to reallocate her expected income stream between the two periods. Note that she compensates for any discrepancy between her subjective discount factor and the interest rate. Second, she saves more when future prospects are more uncertain. As will be seen in the next section, financial innovation affects the precautionary component by modifying the portfolio $\tilde{m}^{A}$ and by reducing the undiversifiable income risk $\tilde{e}^{h A^{\perp}}$. 
The consumption of the non-participating investor is obtained from Proposition 1 by setting $A=\{0\}$ and $\kappa=0$. The agent saves

$$
\theta_{0}^{h, n}=\frac{R}{1+R}\left[e_{0}^{h}-\mathbb{E} \tilde{e}^{h}+\frac{1}{\chi} \ln (R \beta)+\frac{\gamma}{2} \operatorname{Var}\left(\tilde{e}^{h}\right)\right]
$$

in the first period, and consumes $\tilde{c}^{h, n}=\tilde{e}^{h}+\theta_{0}^{h, n}$ in the second. She thus bears the entire endowment risk in her final consumption, and her precautionary demand for the bond depends on the whole variance of future income.

The investor makes her participation decision by comparing utility under entry and non-entry. In the CARA-normal case, this reduces to maximizing the certainty equivalent $\mathbb{E} \widetilde{c}^{h}-\gamma \operatorname{Var}\left(\widetilde{c}^{h}\right) / 2$. We can easily check that the benefit of trading risky assets is $\gamma \operatorname{Var}\left(\tilde{e}^{h A}-\tilde{m}^{A}\right) / 2$, while the opportunity cost is $\kappa R$. This leads to

Theorem 1 (Entry Condition). The investor trades risky assets when

$$
\frac{\gamma}{2} \operatorname{Var}\left(\tilde{e}^{h A}-\tilde{m}^{A}\right)>\kappa R,
$$

and is indifferent between entry and non-entry if the relation holds as an equality.

Relation (2.3) has a simple geometric interpretation in $L^{2}(\Omega)$, which is illustrated in Figure 1. The agent trades risky assets if the distance between her income risk $\tilde{e}^{h A}$ and her optimal portfolio $\tilde{m}^{A}$ is larger than $\sqrt{2 \kappa R / \gamma}$. The trader pays the entry fee only if her initial position is sufficiently different from the optimum, as is standard in decision problems with adjustment costs.

The theorem has a natural interpretation when all agents have a positive exposure to certain classes of risks. Participants with low exposure to marketable shocks buy the corresponding assets to earn a risk premium; these agents are called speculators or investors. ${ }^{12}$ On the other hand, agents with high exposure hedge by shorting the corresponding risky assets; these agents are hedgers or issuers. The model thus closely matches the type of risk-sharing examined in the futures literature.

\footnotetext{
${ }^{12}$ Massa and Simonov (2002) document empirically the substantial impact of labor income risk on individual participation. In particular, households are less likely to invest in financial markets when their income has a higher correlation with a diversified stock portfolio. These findings are consistent with entry condition (2.3) since the participation benefit can be rewritten as $\gamma\left[-2 \operatorname{Cov}\left(\tilde{m}^{A} ; \tilde{e}^{h}\right)+\operatorname{Var}\left(\tilde{e}^{h A}\right)+\operatorname{Var}\left(\tilde{m}^{A}\right)\right] / 2$.
} 


\subsection{Equilibrium}

Let $\mathcal{P} \subseteq H$ denote the set of participants in the risky asset markets. When the class of indifferent agents has measure zero, we can write

$$
\mathcal{P}=\left\{h \in H: \gamma \operatorname{Var}\left(\tilde{e}^{h A}-\widetilde{m}^{A}\right) / 2 \geq \kappa R\right\}
$$

Market participants can have different income risk characteristics than the entire population. We will show in Sections 3 and 4 that this difference is a driving element of the model. ${ }^{13}$ While $\tilde{e}$ denotes the mean income in the population, we define the average endowment of participants as $\tilde{e}^{p}=\int_{\mathcal{P}} \tilde{e}^{h} d \mu^{p}(h)$, where $\mu^{p}$ is the conditional measure $\mu / \mu(\mathcal{P}) \cdot{ }^{14}$

In equilibrium, the common consumption risk $\tilde{m}^{A}$ coincides with the average tradable income risk of participants:

$$
\tilde{m}^{A}=\tilde{e}^{p A}
$$

We also establish

Theorem 2 (Asset Prices). In equilibrium, an asset $\tilde{a}$ is worth

$$
\pi(\tilde{a})=\left[\mathbb{E} \tilde{a}-\gamma \operatorname{Cov}\left(\tilde{e}^{p}, \tilde{a}\right)\right] / R .
$$

The interest rate satisfies

$$
\ln R=\ln R_{0}+\chi \mu(\mathcal{P})\left[\kappa+\frac{\gamma}{2} \int_{\mathcal{P}} \operatorname{Var}\left(\tilde{e}^{h A}-\tilde{e}^{p A}\right) d \mu^{p}(h)\right],
$$

where $\ln R_{0}=\ln (1 / \beta)+\chi\left(\mathbb{E} \tilde{e}-e_{0}\right)-(\chi \gamma / 2) \int_{H} \operatorname{Var}\left(\tilde{e}^{h}\right) d \mu(h)$.

The participation set and asset prices are jointly determined by $(2.4)-(2.7)$.

An asset is valuable if it provides a hedge against the consumption risk of participants. Since entry is endogenous, financial innovation can change the market endowment $\tilde{e}^{p}$, and therefore the price $\pi(\tilde{a}) / R^{-1}=\mathbb{E} \tilde{a}-\gamma \operatorname{Cov}\left(\tilde{e}^{p}, \tilde{a}\right)$ of a risky asset relative to the bond. As noted by Oh (1996), such a channel does not exist in a CARA-normal economy with a fixed set of traders: an increase in the span then has no effect on $\operatorname{Cov}\left(\tilde{e}^{p}, \tilde{a}\right)$ and thus on the price of a risky asset relative to

\footnotetext{
${ }^{13}$ Heaton and Lucas (2000) show the empirical validity of this distinction.

${ }^{14}$ More specifically, the conditional measure $\mu^{p}$ is $\mu / \mu(\mathcal{P})$ if $\mu(\mathcal{P})>0$, and identically zero otherwise.
} 
the bond. The possible effect of financial innovation on the risk premium thus crucially relies on the endogeneity of participation in our model.

The equilibrium interest rate $R$ is influenced by two economic effects corresponding to the last two terms of (2.7). First, the interest rate tends to be higher when more first period resources $\kappa \mu(\mathcal{P})$ are absorbed in the entry process. The second term of (2.7) corresponds to the precautionary motive. The variance of individual consumption is $\operatorname{Var}\left(\tilde{e}^{p A}\right)+\operatorname{Var}\left(\tilde{e}^{h A^{\perp}}\right)$ if an agent participates, and $\operatorname{Var}\left(\tilde{e}^{h A}\right)+\operatorname{Var}\left(\tilde{e}^{h A^{\perp}}\right)$ otherwise. Entry thus reduces on average the variance of consumption by

$$
\int_{\mathcal{P}} \operatorname{Var}\left(\tilde{e}^{h A}\right) d \mu^{p}(h)-\operatorname{Var}\left(\tilde{e}^{p A}\right)=\int_{\mathcal{P}} \operatorname{Var}\left(\tilde{e}^{h A}-\tilde{e}^{p A}\right) d \mu^{p}(h) .
$$

This term is large when many agents participate or many hedging instruments are available. The financial markets then permit agents to greatly reduce their risk exposure, which dampens their precautionary motive, reduces the demand for the riskless asset, and leads to an increase in the equilibrium interest rate. ${ }^{15}$

The entry condition (2.3) suggests that a lower fee or improved spanning tends to encourage entry. For instance when the cost $\kappa$ is infinite, no agent trades risky assets and the equilibrium interest rate equals $R_{0}$. The equilibrium set of participants, however, may not increase monotonically with the financial structure. This is because the entry condition (2.3) depends on the endogenous variables $\tilde{e}^{p}$ and $R$. When new assets are added, a participating agent $h$ may leave the market because the diversification benefit $\gamma \operatorname{Var}\left(\tilde{e}^{h A}-\widetilde{e}^{p A}\right) / 2$ has dropped or the opportunity cost has increased. Sections 3 and 4 will provide examples of such behaviors.

The effect of financial innovation on the interest rate is easily predicted when the average endowment of participants remains constant.

Proposition 2. Financial innovation leads to a higher interest rate when the mean endowment $\tilde{e}^{p}$ is unchanged.

The proof has a straightforward intuition. A lower interest rate would reinforce the favorable effect of financial innovation on entry and lead, by (2.7), to a higher interest rate - a contradiction. Thus if the participants' average endowment does not vary, existing asset prices necessarily decrease with financial innovation. Changes

\footnotetext{
${ }^{15}$ This equation is thus consistent with the well-known effect that financial innovation increases the interest rate when the participation structure is exogenous (Weil, 1992; Elul, 1997).
} 
in $\tilde{e}^{p}$ thus play a crucial role in determining the impact of financial innovation on asset prices. To better understand this role, we now introduce a factor model of risk exposure.

\section{Economies with a Unique Risk Factor}

We consider in this section an economy with a unique factor $\tilde{\varepsilon}$ that linearly affects all incomes. The endowment of each investor $h$ is specified as

$$
\tilde{e}^{h}=\mathbb{E} \tilde{e}^{h}+\varphi^{h} \tilde{\varepsilon},
$$

where $\varphi^{h}$ is the individual risk loading. The model is tractable when the shock and the assets are jointly normal. Without loss of generality, we assume that $\tilde{\varepsilon}$ has a standard distribution $\mathcal{N}(0,1)$ and generates a non-negative average loading $\bar{\varphi}$ in the population. ${ }^{16}$ The cross-sectional distribution of $\varphi$ is specified by a measure $\mu$ on the real line. To clarify the exposition, we assume that the measure $\mu$ has a continuous density $f(\varphi)$, whose support is the nonnegative interval $[0, \infty) \cdot{ }^{17}$

When financial markets are incomplete, existing securities span only partially the common shock. The projection of $\tilde{\varepsilon}$ on the asset span, $\tilde{\varepsilon}^{A}=\sum_{i=1}^{J} \operatorname{Cov}\left(\tilde{\varepsilon}^{A}, \widetilde{a}_{j}\right) \widetilde{a}_{j}$, is the tradable component of the factor. The corresponding variance

$$
\alpha=\operatorname{Var}\left(\tilde{\varepsilon}^{A}\right)
$$

quantifies the insurable fraction of the risk $\tilde{\varepsilon}$ and thus represents a useful index of market completeness. Since $\tilde{\varepsilon}$ has unit variance, the index $\alpha$ is contained between 0 and 1 . The values $\alpha=0$ and $\alpha=1$ respectively correspond to the absence of risky assets $(A=\{0\})$ and the full marketability of the shock $(\tilde{\varepsilon} \in A)$. Intermediate values of $\alpha$ arise when agents can only trade the bond and a risky asset imperfectly correlated with the aggregate shock.

The portfolio $\tilde{\varepsilon}^{A}$ and the index $\alpha$ have direct empirical interpretations. We obtain $\tilde{\varepsilon}^{A}$ by regressing the factor $\tilde{\varepsilon}$ on the asset payoffs. The determination coefficient $R^{2}$ then provides an estimate of the completeness index $\alpha$. This approach is easily implemented when the factor represents GDP or an aggregate shock that is not directly tradable on organized exchanges (Roll, 1977). The introduction of a non-redundant asset increases the index $\alpha$ and helps market participants hedge

\footnotetext{
${ }^{16}$ Purely idiosyncratic shocks are ruled out in this section for expositional simplicity.

${ }^{17}$ The theorems of this section are in fact proved for densities $f(\varphi)$ with arbitrary unbounded supports.
} 
more closely the risk $\tilde{\varepsilon}$. Since macroeconomic variables such as GDP are often observed with measurement errors and lags, improvements in national accounting can also lead to more precise hedging and thus a higher $\alpha$.

\subsection{Participation Structure}

We infer from Section 2 the equilibrium of the one-factor economy. Let $\varphi^{p}$ denote the average loading of participants:

$$
\varphi^{p}=\int_{\mathcal{P}} \varphi d \mu^{p}(\varphi)
$$

The participation set contains agents whose loading $\varphi$ is sufficiently different from $\varphi^{p}:$

$$
\mathcal{P}=\left\{\varphi \in \mathbb{R}:\left|\varphi-\varphi^{p}\right| \geq \Lambda\right\},
$$

where $\Lambda=\sqrt{2 \kappa R /(\alpha \gamma)} .{ }^{18}$ We note that $\Lambda$ is the half-width of the non-participation region, and henceforth call it the non-participation parameter. $\Lambda$ increases with the entry $\operatorname{cost} \kappa$ and the interest rate $R$, and decreases with the completeness index $\alpha$ and the risk aversion $\gamma$. Thus financial innovation, either in the form of a lower entry fee or an increase in spanning, tends to decrease $\Lambda$. The participation set is illustrated in Figure 2. Agents $\varphi \geq \varphi^{p}+\Lambda$ are hedgers who trade assets in order to reduce their risk exposure. Conversely, agents with loadings $\varphi \leq \varphi^{p}-\Lambda$ are speculators who increase their consumption risk in order to earn a higher return.

The equilibrium calculation is simplified by the following observation: $\varphi^{p}$ is both the average loading and the midpoint of the participation set. ${ }^{19}$ As shown in Appendix B, these restrictions impose that a unique midpoint $\varphi^{p}$ is consistent with a given half-width $\Lambda$ :

Property 1 (Participation Set). For any non-participation parameter $\Lambda \geq 0$, there exists a unique loading $\varphi^{p}(\Lambda)$ satisfying conditions (3.2) and (3.3). The corresponding participation sets $\mathcal{P}_{\Lambda}=\left(-\infty ; \varphi^{p}(\Lambda)-\Lambda\right] \cup\left[\varphi^{p}(\Lambda)+\Lambda ;+\infty\right)$ are nested and decreasing in $\Lambda: \mathcal{P}_{\Lambda^{\prime}} \subseteq \mathcal{P}_{\Lambda}$ for all $\Lambda \leq \Lambda^{\prime}$.

\footnotetext{
${ }^{18}$ Agent $h$ trades risky assets if the participation benefit is larger than the opportunity cost: $\alpha \gamma\left(\varphi^{h}-\varphi^{p}\right)^{2} / 2 \geq \kappa R$, or equivalently $\left|\varphi^{h}-\varphi^{p}\right| \geq \Lambda$. When assets have no correlation with the risk factor $(\alpha=0)$, the participation set is empty under costly entry $(\kappa>0)$ and indeterminate under free entry $(\kappa=0)$.

${ }^{19}$ The loading $\varphi^{p}$ satisfies $\int_{-\infty}^{\varphi^{p}-\Lambda}\left(\varphi-\varphi^{p}\right) f(\varphi) d \varphi+\int_{\varphi^{p}+\Lambda}^{\infty}\left(\varphi-\varphi^{p}\right) f(\varphi) d \varphi=0$, which implicitly defines $\varphi^{p}$ as a function of $\Lambda$.
} 
When the midpoint $\varphi^{p}$ is exogenously fixed, it is clear that the sets $\left(-\infty ; \varphi^{p}-\right.$ $\Lambda] \cup\left[\varphi^{p}+\Lambda ;+\infty\right)$ are decreasing with the non-participation parameter $\Lambda$. We show in the Appendix that the property also holds when the midpoint $\varphi^{p}(\Lambda)$ varies endogenously. Furthermore since the sets $\mathcal{P}_{\Lambda}$ are nested, the half-width $\Lambda$ provides a precise ordering of the participation structure. A high $\Lambda$ corresponds to a small set $\mathcal{P}_{\Lambda}$ and thus a low participation rate $\mu\left(\mathcal{P}_{\Lambda}\right)$.

The midpoint $\varphi^{p}$ controls the pricing of risk. Entrants have average income $\tilde{e}^{p}=\mathbb{E} \tilde{e}^{p}+\varphi^{p}\left(\tilde{\varepsilon}^{A}+\tilde{\varepsilon}^{A^{\perp}}\right)$ and individual random consumption

$$
\widetilde{c}^{h}=\mathbb{E} \widetilde{c}^{h}+\varphi^{p} \tilde{\varepsilon}^{A}+\tilde{e}^{h A^{\perp}} .
$$

We note that the marketable consumption risk $\varphi^{p} \tilde{\varepsilon}^{A}$ is identical for all participants. In equilibrium, the average loading $\varphi^{p}$ determines the covariance between a marketed security $\widetilde{a}$ and individual consumption: $\operatorname{Cov}\left(\widetilde{c}^{h}, \widetilde{a}\right)=\varphi^{p} \operatorname{Cov}(\tilde{\varepsilon}, \widetilde{a})$, and therefore the risk premium.

Financial innovation, either in the form of new assets or lower entry costs, affects $\varphi^{p}$ through changes in $\Lambda$. The impact of innovation on the average loading $\varphi^{p}$ and the risk premium therefore depends on the cross-sectional distribution of risk, as is now shown.

Property 2 (Monotonicity of Average Loading). When the loading density verifies the skewness condition

$$
f\left(\varphi^{p}-\Lambda\right)>f\left(\varphi^{p}+\Lambda\right),
$$

the average loading $\varphi^{p}$ locally increases with the non-participation parameter $\Lambda$.

Figure 2 illustrates the mechanism underlying this key result. When $\Lambda$ decreases, the skewness of the loading density implies that more agents enter to the left (speculators) than to the right (hedgers) of $\varphi^{p}$, which pushes down the average consumption loading $\varphi^{p}$.

To develop intuition, we now analyze the effect of financial innovation on the risk premium in an economy in which the interest rate is exogenously fixed. The entry condition $\Lambda=\sqrt{2 \kappa R /(\alpha \gamma)}$ expresses the non-participation parameter as a function of purely exogenous quantities. A higher completeness index $\alpha$ (or a lower transaction cost $\kappa$ ) reduces the half-width $\Lambda$ and thus increases the participation set $\mathcal{P}_{\Lambda}$. The implied movement in $\varphi^{p}$ controls changes in risk pricing. Consider an asset $\widetilde{a}$ that has positive correlation with the factor, and let $\widetilde{R}_{a}=\widetilde{a} / \pi(\widetilde{a})$ denote 
the random (gross) return. By Theorem 2, the relative risk premium satisfies

$$
\frac{\mathbb{E} \widetilde{R}_{a}-R}{R}=\frac{\gamma \varphi^{p} \operatorname{Cov}(\widetilde{a}, \tilde{\varepsilon})}{\mathbb{E} \tilde{a}-\gamma \varphi^{p} \operatorname{Cov}(\widetilde{a}, \tilde{\varepsilon})}
$$

The higher $\alpha$ (or lower $\kappa$ ) due to financial innovation reduces the participation parameter $\Lambda$ and induces the entry of new agents. Under skewness condition (3.4), a majority of the new entrants has a low exposure and reduces the covariance between the participants' average loading and the asset. Financial innovation thus simultaneously induces higher participation and a reduction in the risk premium. These results illustrate the role of the loading density $f(\varphi)$ for the comparative statics of asset prices.

\subsection{General Equilibrium}

We now extend the analysis to the case of an endogenous interest rate. The entry condition can be rewritten

$$
R_{1}(\Lambda)=\alpha \gamma \Lambda^{2} /(2 \kappa)
$$

The equilibrium of the bond market implies

$$
R_{2}(\Lambda)=R_{0} \exp \left\{\chi \mu\left(\mathcal{P}_{\Lambda}\right)\left[\kappa+\alpha \gamma\left(\operatorname{Var}_{\mathcal{P}_{\Lambda}} \varphi\right) / 2\right]\right\}
$$

where $\operatorname{Var}_{\mathcal{P}_{\Lambda}}(\varphi)=\int_{\mathcal{P}_{\Lambda}}\left(\varphi-\varphi^{p}\right)^{2} d \mu^{p}(\varphi)$ denotes the variance of the participants' loadings. In Figure 3, we graph these functions in the $(\Lambda, R)$ plane. An equilibrium corresponds to the intersection of these two curves. The quadratic function $R_{1}(\Lambda)$ is increasing, while $R_{2}(\Lambda)$ monotonically decreases with $\Lambda$. This helps establish

Theorem 3 (Existence and Uniqueness). There exists a unique equilibrium.

Figure 3 allows us to analyze the impact of financial innovation. An increase in $\alpha$ pushes up both curves in the figure, implying a higher interest rate and an ambiguous change in the non-participation parameter $\Lambda$.

Proposition 3 (Impact of Financial Innovation). The riskless rate $R$ increases with financial innovation. As the completeness index $\alpha$ increases from 0 to 1 , the set of participants $\mathcal{P}$ has two possible behaviors. It is either monotonically increasing; or there exists $\alpha^{*} \in(0,1)$ such that $\mathcal{P}$ increases on $\left[0, \alpha^{*}\right]$ and decreases on $\left[\alpha^{*}, 1\right]$. 
The two behaviors are illustrated in Figure 4. The ambiguous effect of financial innovation on market participation has a simple intuition. On one hand, a higher $\alpha$ increases the diversification benefit $\alpha \gamma\left(\varphi^{h}-\varphi^{p}\right)^{2} / 2$ of trading risky assets and encourages entry. On the other hand, new assets reduce the precautionary motive and increase the interest rate, thus discouraging participation. In empirical settings, we expect that the favorable effect of improved diversification, which stems from risk aversion, will tend to dominate the adverse effect of the precautionary motive. $^{20}$

The one-factor model may help explain a number of features that have characterized financial markets in the past three decades. New financial instruments encouraged investors to participate in financial markets, which led to a reduction in the precautionary motive and in the covariance between stockholder consumption and the aggregate shock. These two effects in turn increased the interest rate and reduced the risk premium. ${ }^{21}$ Note that this argument is consistent with earlier empirical findings. Mankiw and Zeldes (1991) thus show that the consumption of stockholders tends to be more correlated with the market than the consumption of non-stockholders. As financial innovation leads more people to enter the market, the risk premium falls. We leave the empirical exploration of this mechanism to further research.

In this section, financial innovation consists of providing a better hedge against a common risk factor. In practice, however, households and firms face multiple sources of income shocks, and innovation often permits to hedge classes of risk that had been previously uninsurable. For this reason, we next examine a multifactor model of risk.

\footnotetext{
${ }^{20}$ The global monotonicity results of Proposition 3 are proven in Appendix B using a single crossing argument. Additional insights can be gained by examining the local sensitivity of $R_{1}$ and $R_{1}$ to the completeness index $\alpha$. Let $\eta_{X, \alpha}=d \ln X / d \ln \alpha$ denote the elasticity of an endogenous quantity $X$. We infer from (3.5) that $\eta_{\Lambda, \alpha}=\left(\eta_{R, \alpha}-1\right) / 2$. Financial innovation increases the set of participants $\left(\eta_{\Lambda, \alpha}<0\right)$ if it has a weak impact on the interest rate $\left(\eta_{R, \alpha}<1\right)$. Condition (3.5) also implies that the elasticity of $R_{2}(\Lambda)$ with respect to $\alpha$ increases with the dispersion of the participants' loadings $\operatorname{Var}_{\mathcal{P}_{\Lambda}} \varphi$. When traders have very heterogeneous incomes, financial innovation allows agents to greatly reduce their average consumption risk, and thus has a strong impact on the interest rate. This explains why participation is non-monotonic in Figure 4 for the loading density with the highest variance.

${ }^{21}$ As shown in Appendix B, a higher entry cost implies a higher risk premium under condition (3.4). Like models with exogenously restricted participation (e.g. Basak and Cuoco, 1998), our framework thus helps explain the equity premium puzzle.
} 


\section{Multifactor Economies}

We now investigate an economy with a finite number of risk factors $\left(\tilde{\varepsilon}_{1}, . ., \tilde{\varepsilon}_{L}\right)$, which correspond to macroeconomic or sectoral shocks affecting individual income. For instance, $\tilde{\varepsilon}_{1}$ could be an aggregate risk, and $\tilde{\varepsilon}_{2}, . ., \tilde{\varepsilon}_{L}$ industry or sector-specific shocks. We specify the income of each investor $h$ as

$$
\tilde{e}^{h}=\mathbb{E} \tilde{e}^{h}+\sum_{\ell=1}^{L} \varphi_{\ell}^{h} \tilde{\varepsilon}_{\ell}
$$

and denote by $\varphi^{h}=\left(\varphi_{1}^{h}, \ldots, \varphi_{L}^{h}\right)$ the vector of individual loadings. The model is tractable when the risk factors and the asset payoffs are jointly normal. Without loss of generality, we normalize the factors to have unit variances and no mutual correlation: $\left(\tilde{\varepsilon}_{1}, . ., \tilde{\varepsilon}_{L}\right) \sim \mathcal{N}(0, I)$. The distribution of factor loadings in the population is specified by a continuous density $f(\varphi)$ on $\mathbb{R}^{L}$.

The factors may not be fully tradable when financial markets are incomplete. As in the previous section, it is useful to consider their projections $\tilde{\varepsilon}_{\ell}^{A}=$ $\sum_{j=1}^{J} \operatorname{Cov}\left(\tilde{\varepsilon}_{\ell}, \tilde{a}_{j}\right) \tilde{a}_{j}$ on the asset span. We interpret $\tilde{\varepsilon}_{\ell}^{A}$ as the marketable component of factor $\ell$, which can be estimated by regressing $\tilde{\varepsilon}_{\ell}$ on asset payoffs. We conveniently stack the projected factors in a vector $\tilde{\varepsilon}^{A}=\left(\tilde{\varepsilon}_{1}^{A}, . ., \tilde{\varepsilon}_{L}^{A}\right)$. The covariance matrix $\Sigma^{A}=\operatorname{Var}\left(\tilde{\varepsilon}^{A}\right)$ is a generalized index of market completeness, whose diagonal coefficients $\alpha_{\ell}=\operatorname{Var}\left(\tilde{\varepsilon}_{\ell}^{A}\right)$ quantify the insurable fraction of each factor.

We assume for simplicity that the projected factors are mutually uncorrelated: $\operatorname{Cov}\left(\tilde{\varepsilon}_{\ell}^{A}, \tilde{\varepsilon}_{k}^{A}\right)=0$ for all distinct $\ell$ and $k$. In the next subsections, this hypothesis will make it more striking that the improved marketability of factor $\ell$ affects the risk premium on an uncorrelated component $\tilde{\varepsilon}_{k}^{A}$. The covariance matrix is then diagonal:

$$
\Sigma^{A}=\left[\begin{array}{lll}
\alpha_{1} & & \\
& \ddots & \\
& & \alpha_{L}
\end{array}\right],
$$

with coefficients $\alpha_{\ell}=\operatorname{Var}\left(\tilde{\varepsilon}_{\ell}^{A}\right)$ contained between 0 and 1 . We note that $\Sigma^{A}$ is equal to zero when there are no assets, and to the identity matrix when markets are complete.

The equilibrium calculation follows directly from Section 2. By (4.1), the mean endowment of participants satisfies $\tilde{e}^{p}=\mathbb{E} \tilde{e}^{p}+\sum_{\ell=1}^{L} \varphi_{\ell}^{p} \tilde{\varepsilon}_{\ell}$, where $\varphi_{\ell}^{p}$ represents the traders' average exposure to factor $\ell$. The equilibrium of financial markets 
implies the relations $\pi(\tilde{a})=\left[\mathbb{E} \tilde{a}-\gamma \operatorname{Cov}\left(\tilde{e}^{p}, \tilde{a}\right)\right] / R$ and

$$
\ln R=\ln R_{0}+\chi \mu(\mathcal{P})\left[\kappa+\frac{\gamma}{2} \sum_{i=1}^{L} \alpha_{i} \operatorname{Var}_{\mathcal{P}}\left(\varphi_{i}\right)\right]
$$

where $\ln R_{0}=\ln (1 / \beta)+\chi\left(\mathbb{E} \widetilde{e}-e_{0}\right)-(\gamma \chi / 2) \sum_{i=1}^{L} \mathbb{E}\left(\varphi_{i}^{2}\right)$. These equations suggest that when the utility coefficients $\gamma$ and $\chi^{-1}$ are large, financial innovation generates both substantial variations in the pricing of risk and small movements in the interest rate.

By entry condition (2.3), the participation set depends on the completeness index of each factor:

$$
\mathcal{P}=\left\{\varphi: \frac{\gamma}{2} \sum_{\ell=1}^{L} \alpha_{\ell}\left(\varphi_{\ell}-\varphi_{\ell}^{p}\right)^{2} \geq \kappa R\right\}
$$

When all the coefficients $\alpha_{\ell}$ are strictly positive, the participants are located outside an ellipsoid centered at $\varphi^{p}=\left(\varphi_{1}^{p}, . ., \varphi_{L}^{p}\right) .{ }^{22}$ The half-widths $\Lambda_{\ell}=\sqrt{2 \kappa R /\left(\alpha_{\ell} \gamma\right)}$ of the ellipsoid along each axis depend on the completeness index $\alpha_{\ell}$ and the endogenous interest rate. We show in Appendix C:

Theorem 4 (Existence and Uniqueness). There exists a unique equilibrium.

The proof begins by establishing that the vector $\Lambda=\left(\Lambda_{1}, . ., \Lambda_{L}\right)$ define a unique participation set $\mathcal{P}_{\Lambda}$. In contrast to the one-factor case, however, $\mathcal{P}_{\Lambda}$ can move in more than one direction and thus need not be decreasing (as a set) in each component $\Lambda_{\ell}$. The market clearing of the bond uniquely determines the interest rate $R$ and the half-widths $\Lambda_{\ell}=\sqrt{2 \kappa R /\left(\alpha_{\ell} \gamma\right)}$. The proof also provides a useful algorithm for the numerical computation of equilibrium. We now examine the comparative statics of participation and asset prices with respect to financial innovation.

\subsection{Financial Innovation and the Risk Premium}

The one-factor model shows that financial innovation can reduce the risk premium of securities correlated with the aggregate shock. In a multifactor economy, the improved marketability of a factor can also have pricing effects on uncorrelated assets. Consider for instance an economy with two factors: $\widetilde{\varepsilon}_{1}$ is an aggregate

\footnotetext{
${ }^{22}$ The participants are located outside a cylinder when some coefficients $\alpha_{\ell}$ are equal to zero.
} 
risk to which all investors are positively exposed, and $\widetilde{\varepsilon}_{2}$ is purely idiosyncratic or distributional. Let $\tilde{a}=\mathbb{E} \widetilde{a}+\tilde{\varepsilon}_{1}^{A}, \pi(\tilde{a})>0$, denote an asset or stock that is only correlated with the aggregate risk. ${ }^{23}$ By equation (2.6), the stock has relative premium

$$
\frac{\mathbb{E} \widetilde{R}_{a}-R}{R}=\frac{\gamma \varphi_{1}^{p} \alpha_{1}}{\mathbb{E} \widetilde{a}-\gamma \varphi_{1}^{p} \alpha_{1}} .
$$

When participation is exogenously fixed, the consumption loading $\varphi_{1}^{p}$ is constant and the improved marketability of the idiosyncratic shock $\tilde{\varepsilon}_{2}$ does not affect the premium (4.4). In our model, however, innovation can affect the set of participants, the consumption loading $\varphi_{1}^{p}$ and therefore the equity premium.

To further illustrate this mechanism, assume that the stock $\tilde{a}$ is the only asset initially traded $\left(\alpha_{2}=0\right)$. By (4.3), non-participants have loadings $\varphi_{1}$ that are close to the market average: $\left|\varphi_{1}-\varphi_{1}^{p}\right| \leq \sqrt{2 \kappa R /\left(\alpha_{1} \gamma\right)}$. When the index $\alpha_{2}$ increases, some agents become willing to pay the entry cost because their exposure $\varphi_{2}$ to the idiosyncratic risk is sufficiently different from the average $\varphi_{2}^{p}$. These new participants also trade the stock $\tilde{a}$ to achieve optimal diversification. The risk premium on $\tilde{a}$ declines if a majority of the new entrants have low exposure to the aggregate shock $\left(\varphi_{1}<\varphi_{1}^{p}\right)$ and increase the demand for the stock. We expect this logic to hold when the distribution of $\varphi_{1}$ is skewed towards the origin, consistent with the intuition developed in the one-factor case.

A simple simulation of the cross-sectoral effect is presented in Figure 5. We assume for simplicity that exposures to the aggregate and idiosyncratic risks are independent in the population. The cross-sectional loading density is then $f\left(\varphi_{1}, \varphi_{2}\right)=f_{1}\left(\varphi_{1}\right) f_{2}\left(\varphi_{2}\right)$. This hypothesis makes it perhaps more surprising that increased marketability of the idiosyncratic risk modifies the equity premium. We specify $f_{2}\left(\varphi_{2}\right)$ to be symmetric around zero, which implies that $\varphi_{2}^{p}=0$ in equilibrium. We discuss the choice of parameters in Appendix C. The average payoff of the stock is selected to obtain a risk premium $\mathbb{E} \widetilde{R}_{a}-R$ equal to $7 \%$ before the introduction of new contracts $\left(\alpha_{2}=0\right)$. In the absence of a futures market, the net interest rate equals $1 \%$ and the standard deviation of the stock $\left[\operatorname{Var}\left(\widetilde{R}_{a}\right)\right]^{1 / 2}$ is $15 \%$, implying an initial Sharpe ratio of about $1 / 2$.

In Figures 5A-5D, the solid lines illustrates equilibrium in the endogenous participation economy as $\alpha_{2}$ increases from 0 to 1 . The dashed lines illustrate the

\footnotetext{
${ }^{23}$ While the assets are assumed to be in zero net supply, we easily reinterpret the model in terms of equity by viewing endowment as the sum of a labor income and an exogenous endowment of stocks.
} 
corresponding outcomes when participation is exogenously fixed. For comparison purposes, the participation sets in both economies coincide when $\alpha_{2}=0$. Under fixed participation, innovation only has a very modest impact on the equity premium, the interest rate and volatility. ${ }^{24}$ In contrast, substantial movements are observed when entry is endogenous. The risk premium on the stock declines from $7 \%$ to $4.5 \%$. Providing insurance against the idiosyncratic shock thus substantially decreases the risk premium through changes in participation. Consistent with empirical evidence, the standard deviation of the stock return is almost constant at $15 \%{ }^{25}$ We observe that most of the decline in the risk premium occurs when the hedging coefficient $\alpha_{2}$ increases from 0 to 0.5 . The value $\alpha_{2}=0.5$ also yields values for participation $(60 \%)$ and the real net interest rate $(2.5 \%)$ that are reasonable for the current US economy. This suggests that the cross-sectoral effects induced by financial innovation may be quantitatively significant. ${ }^{26}$ We leave to further research the full empirical assessment of this mechanism.

\subsection{Differential Effects, Participation Turnover and Interest Rate}

We now explore three additional consequences of innovation in the multifactor model: differential changes in sectoral risk premia, simultaneous entry and exit, and a possible reduction of the interest rate.

The previous simulations assumed that the loading density $f_{2}\left(\varphi_{2}\right)$ is symmetric around zero. Participants insure the marketable component of the idiosyncratic shock at no cost, and an asset correlated only with $\widetilde{\varepsilon}_{2}$ yields no risk premium $\left(\varphi_{2}^{p}=0\right)$. We now examine an economy in which the loading density $f_{2}\left(\varphi_{2}\right)$

\footnotetext{
${ }^{24}$ We know from equation (4.4) that financial innovation has no impact on the relative risk premium $\left(\mathbb{E} R_{a}-R\right) / R$. Figure 5 shows that the interest rate $R$ and thus the risk premium $\mathbb{E} R_{a}-R$ are also approximately constant in the calibrated economy when the idiosyncratic risk becomes tradable.

${ }^{25}$ Campbell, Lettau, Malkiel and Xu (2001) document that the volatility of stock market indices have been stationary over the past century.

${ }^{26} \mathrm{An}$ increase in $\alpha_{2}$ reduces the idiosyncratic or background risk of all participants. When utilities are isoelastic (or more generally exhibit decreasing absolute risk aversion), the reduction in background risk increases the demand for the stock and thus further reduces the risk premium. We anticipate that this additional channel substantially amplifies the pricing effect of financial innovation in more general setups. A similar argument is made by Heaton and Lucas (1999, pp. 237-239). Their framework, however, only considers a unique risk factor and asset, and therefore does not permit the distinction between background risk and aggregate shock. We anticipate that their numerical results would be strengthened by the simultaneous reduction of trader exposure to the aggregate and idiosyncratic risks considered in this paper.
} 
has a positive support and is skewed towards the origin. The risks $\widetilde{\varepsilon}_{1}$ and $\widetilde{\varepsilon}_{2}$ are independent sources of aggregate uncertainty that yield positive and possibly distinct premia. Financial innovation can differentially affect asset prices across sectors, and thus have rich effects on the cross-section of expected returns.

The comparative statics analysis of Figure 2 easily extends to the two-factor case. We consider a financial structure with completeness indices $\alpha_{1}$ and $\alpha_{2}$, and assume for simplicity that interest rate $R$ is exogenous. The ellipse delimiting the participation set is illustrated by a solid line in Figure $6 A$. It is centered at $\varphi^{p}$ and has half-width $\Lambda_{\ell}=\sqrt{2 \kappa R /\left(\alpha_{\ell} \gamma\right)}$ along each axis. Consider an increase in the second index from $\alpha_{2}$ to $\alpha_{2}^{\prime}$. Since the interest is fixed, the limiting boundary in the new equilibrium has the same horizontal $\Lambda_{1}$ but a shorter vertical half-width $\Lambda_{2}^{\prime}$. We represent the intermediate ellipse centered at $\varphi^{p}$ with parameters $\Lambda_{1}$ and $\Lambda_{2}^{\prime}$ in dotted lines. Agents in the shaded area have smaller average loadings than $\varphi_{1}^{p}$ and $\varphi_{2}^{p}$, and thus tend to push the new equilibrium set towards the origin. Because these agents are more spread out vertically than horizontally, the induced movement in $\varphi^{p}$ tends to be stronger along the vertical axis, i.e. in the direction of innovation. The increased marketability of the shock $\widetilde{\varepsilon}_{2}$ may thus predominantly influence the risk premium in the second sector.

The new set of participants is delimited by the ellipse centered at $\varphi_{\text {new }}^{p}$ with half-widths $\Lambda_{1}$ and $\Lambda_{2}^{\prime}$, as illustrated in Figure $6 B$. Financial innovation induces simultaneous entry and exit. Agents in the shaded area are initially out of the market. When the new asset is introduced, these agents face lower hedging costs and decide to participate. Agents in the dashed area, on the other hand, are initially investing in financial assets. Lower risk premia reduce the profitability of their investments and result in their leaving the market. The possibility of simultaneous entry and exit is thus an attractive feature of the multifactor model. ${ }^{27} \mathrm{In}$ future work, this property may prove useful to relate the cross-sectional distribution of risk with patterns of entry and exit in US stockownership (e.g. Hurst, Luoh and Stafford, 1998; Vissing-Jørgensen, 2002).

The differential effect is illustrated in Figure 7 on a numerical example. The marginal densities of the factor loadings are identical log-normals. The initial economy has hedging coefficients $\alpha_{1}=\alpha_{2}=\underline{\alpha}$. We assume that the interest rate is endogenous and consider two fixed assets $\widetilde{a}_{\ell}=x_{\ell}+\widetilde{\varepsilon}_{\ell}^{A}(\ell=1,2)$ with a risk premium of $7 \%$. The symmetry of the economy imposes that $x_{1}=x_{2}$.

\footnotetext{
${ }^{27}$ Participation tunover also arises when the distribution of $\varphi_{2}$ is symmetric, as shown in the proof of Proposition 4.
} 
As $\alpha_{2}$ increases from $\underline{\alpha}$ to 1 , both risk premia fall and the effect is stronger for the second asset. The results of the figure are almost unchanged when the net interest rate is exogenously set at $2 \%$. The differential effect is an important feature of the multifactor economy. It distinguishes the introduction of sectorspecific securities from changes affecting all security markets, such as a reduction in taxes or transaction costs.

Multifactor economies also imply novel results for the comparative statics of the interest rate. As discussed in Section 2, the introduction of new assets increases risk-sharing opportunities and weakens the precautionary demand for savings. In models with exogenous participation, this leads to a higher equilibrium interest rate under many specifications, including CARA-normal (Weil, 1992; Elul, 1997). In contrast, the Appendix establishes that when participation is endogenous,

Proposition 4. The interest rate locally decreases with financial innovation in some multifactor economies.

This result has a simple geometric intuition. When new assets are introduced, the movement of $\varphi^{p}$ pushes the ellipse towards a region containing a large number of

participants. In some economies, this effect is sufficiently strong to reduce overall participation and the interest rate.

\section{Conclusion}

This paper develops a tractable asset pricing model with incomplete markets and endogenous participation. Agents receive heterogeneous random incomes determined by a finite number of risk factors. They can borrow or lend freely, but must pay a fixed entry cost to invest in risky assets. Security prices and the participation set are jointly determined in equilibrium. The introduction of non-redundant assets encourages investors to participate in financial markets for hedging and diversification purposes. Under plausible conditions on the cross-sectional distribution of risk, the new entrants reduce the covariance between dividends and trader consumption, which induces a reduction in the risk premium.

This logic is easily demonstrated in a simple one-factor model. Financial innovation also has cross-sectoral effects in economies with multiple sources of risk. When a factor becomes tradable, new agents are drawn to the market in order to manage their risk exposure. Under complementarities in learning or increasing returns to trading activities, the new agents also become active in preexisting 
markets and can modify the risk premia of securities uncorrelated to the factor. This mechanism differentially affects distinct sectors of the economy and thus may have a rich impact on the cross-section of expected returns. Simultaneous entry and exit is another attractive feature of the multifactor model, which could be useful for the analysis of participation turnover in economies with heterogeneous income risks.

This paper suggests several directions for empirical research. Future work could assess the contribution of financial innovation to the decline of the equity premium in the past few decades. Participation changes may also help explain the pricing effects of new derivatives reported in the empirical literature. From a policy perspective, the mechanisms examined in this paper provide useful insights on current debates in public and international economics. When countries face fixed costs to financial integration, the model implies that the creation of new markets can have profound pricing, participation and welfare consequences. An extension of this work could investigate the political economy of the macro markets advocated by Shiller and others. Further research may also evaluate government policies affecting asset creation and participation costs, such as financial regulation, taxes, and social security reform. 


\section{Appendix A - Existence and Constrained Efficiency}

\subsection{Existence}

We prove existence for a convex economy with a finite state space $\Omega=\{1, . ., S\}$. and non-negative consumption sets. The utility $U^{h}$ of every agent is continuous, strongly monotonic and strictly quasi-concave on $\mathbb{R}_{+}^{S+1}$. At prices where agents are indifferent between entry $\left(\theta^{h} \neq 0\right)$ and non-entry $\left(\theta^{h}=0\right)$, individual demand consists of two distinct points. We avoid discontinuities in aggregate demand by assuming that there is a finite number of types $h=1, . ., H$, and a continuum of agents in each type.

Given $q=\left(p_{0}, \pi_{0}, \pi\right)$, let $\widehat{B}^{h}(q)$ denote the set of plans $\left(c_{0}, \theta_{0}, \theta\right)$ satisfying the budget constraints $p_{0}\left(c_{0}+\kappa 1_{\left\{\theta^{h} \neq 0\right\}}\right)+\pi_{0} \theta_{0}+\pi \cdot \theta \leq p_{0} e_{0}^{h}$ and $\tilde{e}^{h}+\theta_{0}+\tilde{a} \cdot \theta \geq 0$. The no-arbitrage set is the open cone $Q=\left\{\left(p_{0}, \Lambda . a_{0}, \ldots, \Lambda . a_{J}\right) ; \quad\left(p_{0}, \Lambda\right) \in \mathbb{R}_{++}^{S+1}\right\}$. Given $q \in Q$, we can calculate the optimal excess demands $Z^{h p}(q) \equiv\left[c_{0}^{h p}(q)+\right.$ $\left.\kappa-e_{0}^{h}, \theta_{0}^{h p}(q), \theta^{h p}(q)\right]$ and $Z^{h n}(q) \equiv\left[c_{0}^{h n}(q)-e_{0}^{h}, \theta_{0}^{h n}(q), 0\right]$ under entry and nonentry. The excess demand correspondence $Z^{h}(q)$ is defined as $Z^{\text {hd }}(q)$ when decision $d \in\{p, n\}$ is strictly optimal, and as the interval $\left[Z^{h p}(q), Z^{h n}(q)\right]$ when the agent is indifferent between entry and non-entry. $Z^{h}(q)$ is homogeneous of degree 0 , upper hemi-continuous and satisfies Walras' law. Consider a vector $\bar{q} \neq 0$ on the frontier of $Q$, and a sequence $\left\{q^{n}\right\}_{n=1}^{\infty}$ of elements of $Q$ converging to $\bar{q}$. Following Hens (1991), it is easy to show that $\inf \left\{\|z\| ; z \in Z^{h}\left(q^{n}\right)\right\} \rightarrow \infty$ and $\inf \{\|z\| ; z \in$ $\left.N Z^{h}\left(q^{n}\right)\right\} \rightarrow \infty$ as $n \rightarrow \infty$, where $M=\left[a_{0}, . ., a_{J}\right]$ and $N=\left[\begin{array}{ll}1 & \\ & M\end{array}\right]$. Since consumption is non-negative, the set $N Z^{h}\left(q^{n}\right) \geq-e^{h}$ is also bounded below. We conclude by standard arguments that an equilibrium exists (Hens, 1991).

\subsection{Constrained Efficiency of Equilibrium}

We consider an equilibrium $\left(R, \pi,\left(c_{0}^{h}, \tilde{c}^{h}, \theta_{0}^{h}, \theta^{h}\right)_{h \in H}\right)$, and assume that there exists a feasible allocation $\left(d_{0}^{h}, \widetilde{d}^{h}\right)_{h \in H}$ such that $U^{h}\left(d_{0}^{h}, \widetilde{d}^{h}\right)>U^{h}\left(c_{0}^{h}, \tilde{c}^{h}\right)$ for all $h$. For every agent, there exists $\left(\eta_{0}^{h}, \eta^{h}\right)$ such that $\widetilde{d}^{h}=\tilde{e}^{h}+\eta_{0}^{h}+\tilde{a} \cdot \eta^{h}$. Since $\left(d_{0}^{h}, \widetilde{d}^{h}\right)$ is strictly preferred to $\left(c_{0}^{h}, \tilde{c}^{h}\right)$, it must be that $d_{0}^{h}+\pi_{0} \eta_{0}^{h}+\pi \cdot \eta^{h}+\kappa 1_{\left\{\eta^{h} \neq 0\right\}}>e_{0}^{h}$. We infer $\int_{H}\left(d_{0}^{h}+\kappa 1_{\left\{\eta^{h} \neq 0\right\}}\right) d \mu(h)>e_{0}$, which contradicts feasibility. 


\section{Appendix B - One-Factor Economies}

\subsection{Participation Set (Proof of Properties 1 and 2)}

For every fixed $\Lambda \geq 0$, the function $G_{\Lambda}\left(\varphi_{p}\right)=\int_{-\infty}^{\varphi_{p}-\Lambda}\left(\varphi-\varphi_{p}\right) d \mu+\int_{\varphi_{p}+\Lambda}^{+\infty}\left(\varphi-\varphi_{p}\right) d \mu$ is continuous and strictly decreasing on $\mathbb{R}$. It also satisfies $\lim _{\varphi_{p} \rightarrow-\infty} G_{\Lambda}\left(\varphi_{p}\right)=+\infty$ and $\lim _{\varphi_{p} \rightarrow+\infty} G_{\Lambda}\left(\varphi_{p}\right)=-\infty$. The equation $G_{\Lambda}\left(\varphi_{p}\right)=0$ has thus a unique solution $\varphi_{p}(\Lambda)$. By the implicit function theorem, the function $\varphi_{p}(\Lambda)$ has derivative

$$
\frac{d \varphi_{p}}{d \Lambda}=-\frac{f\left(\varphi^{p}+\Lambda\right)-f\left(\varphi^{p}-\Lambda\right)}{f\left(\varphi^{p}+\Lambda\right)+f\left(\varphi^{p}-\Lambda\right)+\mu\left(\mathcal{P}_{\Lambda}\right) / \Lambda},
$$

which is contained between -1 and 1 . We conclude that $\varphi^{p}(\Lambda)-\Lambda$ and $\varphi^{p}(\Lambda)+\Lambda$ are respectively decreasing and increasing in $\Lambda$, and thus that $\mathcal{P}_{\Lambda}$ is decreasing.

\subsection{Equilibrium Properties (Proof of Theorem 3 and Proposition 3)}

Existence and Uniqueness. Appendix A establishes the existence of equilibrium in an economy with finite state space and non-negative consumption. We now prove existence and uniqueness in the one-factor CARA-normal case. Consider $H_{0}(\Lambda)=\mu\left(\mathcal{P}_{\Lambda}\right)$ and $H_{1}(\Lambda)=\mu\left(\mathcal{P}_{\Lambda}\right)\left(\operatorname{Var}_{\mathcal{P}_{\Lambda}} \varphi\right)$. The monotonicity of $\mathcal{P}_{\Lambda}$ implies that $H_{0}(\Lambda)$ is decreasing in $\Lambda$. Similarly, the function $H_{1}(\Lambda)=\int_{-\infty}^{\varphi^{p}-\Lambda}(\varphi-$ $\left.\varphi_{p}\right)^{2} f(\varphi) d \varphi+\int_{\varphi^{p}+\Lambda}^{+\infty}\left(\varphi-\varphi_{p}\right)^{2} f(\varphi) d \varphi$ has derivative $H_{1}^{\prime}(\Lambda)=\Lambda^{2} H_{0}^{\prime}(\Lambda)<0$. Equilibrium is determined by (3.5) - (3.6). The function $R_{1}$ is strictly increasing, and $R_{2}$ is decreasing. The difference function $R_{1}(\Lambda)-R_{2}(\Lambda)$ is therefore strictly increasing and maps $[0,+\infty)$ onto $\left[-R_{2}(0),+\infty\right)$. We conclude that there exists a unique equilibrium.

Impact of Financial Innovation. Using Cramer's rule, we check that financial innovation increases the interest rate: $\frac{d R}{d \alpha}>0$. On the other hand, $\frac{d \Lambda}{d \alpha}$ has the same sign as $G(\alpha)-2 \equiv \alpha \chi \gamma H_{1}[\Lambda(\alpha)]-2$. Since $G(0)=0$, the function $\Lambda(\alpha)$ is decreasing on a neighborhood of $\alpha=0$. We also oberve that if $G(\alpha)=2$, then $G^{\prime}(\alpha)>0$. The equations $G(\alpha)=2$ and $\frac{d \Lambda}{d \alpha}=0$ thus have at most one solution on $(0,1]$.

Impact of Entry Fee. Cramer's rule implies that $\frac{d \Lambda}{d \kappa}>0$. A higher entry cost $\kappa$ thus reduces the participation set $\mathcal{P}_{\Lambda}$. 


\section{Appendix C - Multifactor Economies}

\subsection{Existence and Uniqueness of Equilibrium (Proof of Theorem 4)}

The set $\mathcal{P}\left(\varphi^{p}, \Lambda\right)=\left\{\varphi: \sum_{i=1}^{L}\left(\frac{\varphi_{i}-\varphi_{i}^{p}}{\Lambda_{i}}\right)^{2} \geq 1\right\}$ is defined for any $\varphi^{p} \in \mathbb{R}^{L}$ and $\Lambda=\left(\Lambda_{1}, . ., \Lambda_{L}\right) \in \mathbb{R}_{++}^{L}$. We observe

Fact C1. For any $\Lambda \in \mathbb{R}_{++}^{L}$, the equation $\int_{\mathcal{P}\left(\varphi^{p} ; \Lambda\right)}\left(\varphi-\varphi^{p}\right) d \mu(\varphi)=0$ has a unique solution $\varphi_{\Lambda}^{p} \in \mathbb{R}^{L}$.

Proof. We rewrite the equation as a convex optimization problem. Consider $k\left(\varphi ; \varphi^{p}, \Lambda\right)=\left[\sum_{i=1}^{L}\left(\frac{\varphi_{i}-\varphi_{i}^{p}}{\Lambda_{i}}\right)^{2}-1\right] 1_{\mathcal{P}\left(\varphi^{p}, \Lambda\right)}(\varphi)$, where $1_{\mathcal{P}\left(\varphi^{p}, \Lambda\right)}$ denotes the indicator function of $\mathcal{P}\left(\varphi^{p}, \Lambda\right)$. Since $k\left(\varphi ; \varphi^{p}, \Lambda\right)$ is convex in $\varphi^{p}$ and $\mu$ has an unbounded support, the function $K\left(\varphi^{p}, \Lambda\right)=\frac{1}{2} \int_{\mathbb{R}^{L}} k\left(\varphi ; \varphi^{p}, \Lambda\right) d \mu(\varphi)$ is strictly convex in $\varphi^{p}$. A vector $\varphi^{p}$ thus minimizes $K\left(\varphi^{p}, \Lambda\right)$ on $\mathbb{R}^{L}$ if and only if $\frac{\partial K}{\partial \varphi^{p}}=$ $\int_{\mathcal{P}\left(\varphi^{p} ; \Lambda\right)}\left(\varphi-\varphi^{p}\right) d \mu(\varphi)=0$. Since $K$ diverges to $+\infty$ as $\left\|\varphi^{p}\right\| \rightarrow+\infty$, there exists a unique minimizer $\varphi^{p}$.

For every $R>0$, let $\Lambda(R)$ denote the vector with components $\Lambda_{\ell}(R)=$ $\sqrt{2 \kappa R /\left(\alpha_{\ell} \gamma\right)}(1 \leq \ell \leq L)$. It is convenient to define $\varphi^{p}(R) \equiv \varphi_{\Lambda(R)}^{p}$, the set $\mathcal{P}(R) \equiv \mathcal{P}\left[\varphi_{\Lambda(R)}^{p}, \Lambda(R)\right]$, and the function

$$
z(R) \equiv \ln R_{0}+\chi \int_{\mathcal{P}(R)}\left\{\kappa+\frac{\gamma}{2} \sum_{i=1}^{L} \alpha_{i}\left[\varphi_{i}-\varphi_{i}^{p}(R)\right]^{2}\right\} d \mu(\varphi)
$$

We check that $z^{\prime}(R)=\chi \kappa(1+R) \frac{d \mu[\mathcal{P}(R)]}{d R}$, which is weakly negative by Fact $\mathrm{C} 2$ below. We conclude that the equilibrium equation $z(R)=\ln R$ has thus a unique solution.

Fact C2. The mass of participants $\mu[\mathcal{P}(R)]$ is a decreasing function of $R$.

Proof. We first show that the property holds under complete markets: $\alpha_{\ell}=1$ for all $\ell$. For any $R$, the boundary of the participation set $\mathcal{P}(R)$ is a sphere, which is denoted $S(R)$. Given two positive numbers $R$ and $\delta, \delta<R$, we seek to show that $\mu[\mathcal{P}(R)] \leq \mu[\mathcal{P}(R-\delta)]$. The inequality is trivially satisfied when $\mathcal{P}(R) \subseteq \mathcal{P}(R-\delta)$. When $\mathcal{P}(R) \varsubsetneqq \mathcal{P}(R-\delta)$, the intersection of the spheres $S(R)$ and $S(R-\delta)$ is contained in a hyperplane $H$. Consider axes such that $H$ is described by the equation $\varphi_{1}=0$, and the center of gravity $\varphi^{p}(R)=(x, 0 \ldots 0)$ has a positive first coordinate $x$. We check that $\varphi^{p}(R-\delta)$ has coordinates $(y, 0 \ldots 0)$, where $y<x$. 
When the interest rate moves from $R$ to $R-\delta$, agents in $\mathcal{P}_{+}=\mathcal{P}(R-\delta) \backslash \mathcal{P}(R)$ enter, agents in $\mathcal{P}_{-}=\mathcal{P}(R) \backslash \mathcal{P}(R-\delta)$ exit, and agents in $\mathcal{P}_{C}=\mathcal{P}(R) \cap \mathcal{P}(R-\delta)$ participate under both interest rates (Figure 8). Since $\mathcal{P}(R)=\mathcal{P}_{-} \cup \mathcal{P}_{C}$ and $\mathcal{P}(R-\delta)=\mathcal{P}_{+} \cup \mathcal{P}_{C}$, we infer that $\int_{\mathcal{P}_{-}} \varphi_{1} d \mu(\varphi)+\int_{\mathcal{P}_{C}} \varphi_{1} d \mu(\varphi)=x \mu[\mathcal{P}(R)]$, and $\int_{\mathcal{P}_{+}} \varphi_{1} d \mu(\varphi)+\int_{\mathcal{P}_{C}} \varphi_{1} d \mu(\varphi)=y \mu[\mathcal{P}(R-\delta)]$. Substracting these equalities implies

$$
\int_{\mathcal{P}_{+}} \varphi_{1} d \mu(\varphi)-\int_{\mathcal{P}_{-}} \varphi_{1} d \mu(\varphi)=y \mu[\mathcal{P}(R-\delta)]-x \mu[\mathcal{P}(R)]
$$

The left-hand side of the equation is positive because $\mathcal{P}_{+}$is contained in the half-space $\varphi_{1}>0$ and $\mathcal{P}_{-}$is contained in the half-space $\varphi_{1}<0$. Since $x>y$, we infer that $x \mu[\mathcal{P}(R)] \leq y \mu[\mathcal{P}(R-\delta)] \leq x \mu[\mathcal{P}(R-\delta)]$, and conclude that $\mu[\mathcal{P}(R)] \leq \mu[\mathcal{P}(R-\delta)]$ holds under complete markets.

When markets are incomplete, consider the linear rescaling $\varphi_{\ell}^{*}=\Phi_{\ell}(\varphi)=$ $\varphi_{\ell} \sqrt{\alpha_{\ell}}$ and the corresponding measure $\mu^{*}=\mu \circ \Phi^{-1}$. Note that these transformations are independent of $R$. For every $R>0$, the rescaled set $\mathcal{P}^{*}(R)=\Phi[\mathcal{P}(R)]$ has a spherical boundary. We conclude that $\mu[\mathcal{P}(R)]=\mu^{*}\left[\mathcal{P}^{*}(R)\right]$ is decreasing in $R$.

\subsection{Numerical Simulation}

This subsection presents the microeconomic framework used in the simulation of Figure 5. Individual random income is specified as $\widetilde{e}^{h}=e_{0}^{h}\left(1+\sigma_{1} \widetilde{\varepsilon}_{1}\right)+\varphi_{2}^{h} \widetilde{\varepsilon}_{2}$. The individual loading $\varphi_{1}^{h}=\sigma_{1} e_{0}^{h}>0$ is therefore proportional to expected income. ${ }^{28}$ The aggregate endowment in period 1 satisfies $\widetilde{e}=e_{0}\left(1+\sigma_{1} \widetilde{\varepsilon}_{1}\right)$. Without loss of generality, mean income is normalized to unity: $e_{0}=1$.

We specify the cross-sectional distribution of income to be $\operatorname{lognormal}: \ln e_{0}^{h} \sim$ $\mathcal{N}\left(\mu_{z}, \sigma_{z}^{2}\right)$. Since mean income is normalized to $1, \mu_{z}$ and $\sigma_{z}^{2}$ satisfy the restriction $\mu_{z}+\sigma_{z}^{2} / 2=0$. We choose $\mu_{z}=-0.25$, which corresponds to a reasonable Gini coefficient of 0.4 . The standard deviation of aggregate income growth $\sigma_{1}$ is set at 0.04. Since $\varphi_{1}^{h}=\sigma_{1} e_{0}^{h}$, the loading density $f_{1}\left(\varphi_{1}\right)$ is now fully specified.

The loading density $f_{2}\left(\varphi_{2}\right)$ is assumed to be a centered Gaussian $\mathcal{N}\left(0, \sigma_{2}^{2}\right)$ with standard deviation $\sigma_{2}=0.10$. The discount factor is $\beta=0.96$. Since $e_{0}=1$, the coefficients $\gamma$ and $\chi^{-1}$ coincide with relative risk aversion and intertemporal elasticity at the mean endowment point. We choose $\gamma=10$ and $\chi^{-1}=2$. The fraction of mean income used in the entry process is set equal to $\kappa=0.8 \%$.

\footnotetext{
${ }^{28}$ We assume for simplicity that there is no expected growth between the two periods.
} 
The aggregate shock is partially tradable. We choose $\alpha_{1}=0.5$, which is roughly consistent with the correlation between the NYSE value-weighted return and the permanent aggregate labor income shock reported in Campbell, Cocco, Gomes and Maenhout (2001). The stock is a traded asset of the form $\widetilde{a}=x+\widetilde{\varepsilon}_{1}^{A}$. We select $x$ to obtain a risk premium $\mathbb{E} \widetilde{R}_{a}-R$ equal to $7 \%$ before financial innovation $\left(\alpha_{2}=0\right)$.

\subsection{Proof of Proposition 4}

We provide an example in an economy with two uncorrelated factors $\left(\varepsilon_{1}, \varepsilon_{2}\right)$. Letting $\delta=0.01$, we consider $\varphi^{A}=(-2,0), \varphi^{B}=(1+\delta, 0), \varphi^{C}=(2,0), \varphi^{-}=$ $(0,-1+\delta)$ and $\varphi^{+}=(0,1-\delta)$, with respective weights $m^{A}=m^{B}=1 / 5, m^{C}=$ $1 / 10, m^{+}=m^{-}=1 / 4$. The other parameters of the economy are $\gamma=\chi=0.7$, $\kappa=0.3, e_{0}=\mathbb{E} \widetilde{e}=1, \alpha_{2}=0.9$.

A straightforward extension of Theorem 4 implies that a unique equilibrium exists for any $\alpha_{1}$. When $\alpha_{1}=0.55$, we check that the participation set contains all the agents of type $A, C,+$ and - , and the net interest rate is approximately $7.9 \%$. On the other hand when $\alpha_{1}=0.9$, the participation set contains all the agents of type $A, B, C$, and the net interest rate has fallen to $5.7 \%$. 


\section{References}

[1] Abel, A., "The Effects of Investing Social Security Funds in the Stock Market When Fixed Costs Prevent Some Households from Holding Stocks," American Economic Review, 91 (2001), 128-148.

[2] Allen, F., and Gale, D., "Incomplete Markets and Incentives to Set Up an Options Exchange," Geneva Papers on Risk and Insurance Theory, 15 (1990), $17-46$.

[3] Allen, F., and Gale, D., Financial Innovation and Risk Sharing, MIT Press, $(1994 a)$.

[4] Allen, F., and Gale, D., "Limited Market Participation and Volatility of Asset Prices," American Economic Review, 84 (1994b), 933-955.

[5] Angeletos, G. M., and Calvet, L. E., "Incomplete Markets, Growth and the Business Cycle", HIER Working Paper \#1910, Harvard University (2000).

[6] Barro, R., and Sala-i-Martin, X. , "World Interest Rates," in O. J. Blanchard and S. Fischer eds., NBER Macroeconomics Annual, 15-61, MIT Press (1990).

[7] Basak, S., and Cuoco, D., "An Equilibrium Model with Restricted Stock Market Participation," Review of Financial Studies, 11 (1998), 309-341.

[8] Bertaut, C., and Haliassos, M., "Why do so few hold stocks?," Economic Journal, 105 (1995), 1110-1129.

[9] Bewley, T., "The Permanent Income Hypothesis: A Theoretical Formulation," Journal of Economic Theory, 16 (1977), 252-292.

[10] Blanchard, O. J., "Movements in the Equity Premium," Brookings Papers on Economic Activity, 2 (1993), 75-118.

[11] Blume, M., Crockett, J., and I. Friend, "Stock Ownership in the United States: Characteristics and Trends", Survey of Current Business 54 (1974), $16-40$.

[12] Blume, M., and Friend, I., The Changing Role of the Individual Investor: A Twentieth Century Fund Report, New York: Wiley (1978). 
[13] Blume, M., and Zeldes, S., "The Structure of Stockownership in the United States", Working Paper, Wharton School (1993).

[14] Calvet, L., "Incomplete Markets and Volatility," Journal of Economic Theory, 98 (2001), 295-338.

[15] Campbell, J. Y., Cocco, J., Gomes, F., and Maenhout, P., "Investing Retirement Wealth: A Life-Cycle Model", Chapter 11 in Risk Aspects of InvestmentBased Social Security Reform, J. Campbell and M. Feldstein eds., University of Chicago Press (2001). Also reproduced in Campbell and Viceira (2002).

[16] Campbell, J. Y., Lettau, M., Malkiel, B., and Xu, Y., "Have Individual Stocks Become More Volatile? An Empirical Exploration of Idiosyncratic Risk," Journal of Finance, 56 (2001), 1-43.

[17] Campbell, J. Y., and Shiller, R. J., "Valuation Ratios and the Long-Run Stock Market: An Update", in Advances in Behavioral Finance, Volume II, N. Barberis and R. Thaler eds., Russell Sage Foundation (2003).

[18] Campbell, J. Y., and Viceira, L., Strategic Asset Allocation: Portfolio Choice for Long-Term Investors, Oxford University Press (2002).

[19] Cass, D., and Citanna, A., "Pareto Improving Financial Innovation in Incomplete Markets," Economic Theory 11 (1998), 467-494.

[20] Cochrane, J., "Where is the Market Going? Uncertain Facts and Novel Theories," Economic Perspectives XXI (November/December): Federal Bank of Chicago (1997). Also NBER Working Paper No. 6207.

[21] Conrad, J., The Price Effect of Option Introduction, Journal of Finance, 44 (1989), 487-498.

[22] Constantinides, G. M., and Duffie, D., "Asset Pricing with Heterogeneous Consumers," Journal of Political Economy, 104 (1996), 219-240.

[23] Detemple, J., and Jorion, P., "Option Listing and Stock Returns," Journal of Banking and Finance, 14 (1990), 781-801.

[24] Detemple, J., and Selden, L., "A General Equilibrium Analysis of Option and Stock Market Interactions," International Economic Review, 32 (1991), 279-303. 
[25] Duffie, D., and Jackson, M., "Optimal Innovation of Futures Contracts", Review of Financial Studies, 2 (1989), 275-296.

[26] Duffie, D., and Rahi, R., "Financial Market Innovation and Security Design: An Introduction," Journal of Economic Theory 65 (1995), 1-42.

[27] Elul, R., "Financial Innovation, Precautionary Saving and the Risk-Free Rate," Journal of Mathematical Economics, 27 (1997), 113-131.

[28] Fama, E., and French, K., "The Equity Premium," Journal of Finance, 57 (2002), 637-659.

[29] Gollier, C., The Economics of Risk and Time, Cambridge, MA: MIT Press (2001).

[30] Gonzalez-Eiras, M., Chapter 2 in "Essays in Incomplete Markets, Liquidity and Risk-Sharing", Ph.D. Dissertation, MIT, February 2000.

[31] Grossman, S., "An Analysis of the Implications for Stock and Futures Price Volatility of Program Trading and Dynamic Hedging Strategies," in S. Grossman ed.: The Informational Role of Prices, Wicksell Lectures, MIT Press (1989).

[32] Heaton, J., and Lucas, D., "Stock Prices and Fundamentals," NBER Macroeconomics Annual Vol. 14, (1999), 213-242.

[33] Heaton, J., and Lucas, D., "Portfolio Choices and Asset Prices: The Importance of Entrepreneurial Risk," Journal of Finance, 55 (2000), 1163-98.

[34] Hens, T., "Structure of General Equilibrium Models with Incomplete Markets and a Single Consumption Good", Discussion Paper No. A-353, Bonn University (1991).

[35] Hirshleifer, D., "Residual Risk, Trading Costs, and Commodity Futures Risk Premia," Review of Financial Studies, 1 (1988), 173-193.

[36] Honohan, P., "How Interest Rates Changed under Financial Liberalization: A Cross-Country Review", World Bank Working Paper No. 2313 (2000).

[37] Huang, J., and Wang, J., "Market Structure, Security Prices and Informational Efficiency," Macroeconomic Dynamics, 1 (1997), 169-205. 
[38] Hurst, E., Luoh, M. C., and Stafford, F. P., "The Wealth Dynamics of American Families, 1984-1994," Brookings Papers on Economic Activity, 1 (1998), 267-329.

[39] Jochum, C., and Kodres, L. (1998), "Does the Introduction of Futures on Emerging Market Currencies Destabilize the Underlying Currencies?", IMF Working Paper.

[40] Kihlstrom, R., Romer, D., and Williams, S., "Risk Aversion with Random Initial Wealth," Econometrica, 49 (1981), 911-920.

[41] King, M., and J. Leape, "Wealth and Portfolio Composition: Theory and Evidence," NBER Working Paper 1468, Cambridge, MA (1984).

[42] Levine, D., and Zame, W., "Does Market Incompleteness Matter?," Econometrica, 70 (2002), 1805-1840.

[43] Magill, M., and Quinzii, M., Theory of Incomplete Markets, Cambridge, MA: MIT Press (1996).

[44] Mankiw, N. G., and S. Zeldes, "The Consumption of Stockholders and NonStockholders," Journal of Financial Economics, 29 (1991), 97-112.

[45] Massa, M., and Simonov, A., "Do Investors Hedge? Stock Market Participation and Hedging," Working Paper, Stockholm School of Economics (2002).

[46] Mehra, R., and Prescott, E., "The Equity Premium: A Puzzle", Journal of Monetary Economics 15 (1985), 145-162.

[47] Nachman, D., "Preservation of "more risk averse" under expectations," Journal of Economic Theory 28 (1982), 361-368.

[48] Oh, G., "Some Results in the CAPM with Nontraded Endowments," Management Science, 42 (1996), 286-293.

[49] Orosel, G., "Participation Costs, Trend Chasing, and Volatility of Stock Prices," Review of Financial Studies, 11 (1998), 521-557.

[50] Pagano, M., "Endogenous Market Thinness and Stock Price Volatility," Review of Economic Studies, 56 (1989), 269-288. 
[51] Pagano, M., "The Flotation of Companies in the Stock Market," European Economic Review, 37 (1993), 1101-1135.

[52] Poterba, J., and Samwick, A., "Stock Ownership Patterns, Stock Market Fluctuations and Consumption," Brookings Papers on Economic Activity, 2 (1995), 295-357.

[53] Roll, R., "A Critique of the Asset Pricing Theory's Tests - Part 1: On Past and Potential Testability of the Theory," Journal of Financial Economics, 4 (1977), 129-176.

[54] Ross, S., "Options and Efficiency," Quarterly Journal of Economics, 90 (1976), 75-89.

[55] Saito, M., "Limited Participation and Asset Pricing", Working Paper, University of British Columbia (1995).

[56] Shiller, R, The New Financial Order, Princeton University Press (2003).

[57] Sodini, P., Chapter 1 in "Essays in Capital Markets", Ph.D. Dissertation, MIT, August 2001.

[58] Stein, J., "Informational Externalities and Welfare-Reducing Speculation," Journal of Political Economy, 95 (1987), 1123-1145.

[59] Storesletten, K., Telmer, C., and Yaron, A., "Persistent Idiosyncratic Shocks and Incomplete Markets", Working Paper, Carnegie Mellon University (1996).

[60] Telmer, C., "Asset Pricing Puzzles and Incomplete Markets," Journal of Finance, 48 (1993), 1803-1832.

[61] Vissing-Jørgensen, A., "Limited Stock Market Participation", Working Paper, MIT (1997).

[62] Vissing-Jørgensen, A., "Towards an Explanation of Household Portfolio Choice Heterogeneity: Non-Financial Income and Participation Cost Structures", Working Paper, University of Chicago (2002).

[63] Weil, P., "Equilibrium Asset Prices in Economies with Undiversifiable Labor Income Risk," Journal of Economic Dynamics and Control, 16 (1992), 769790 . 


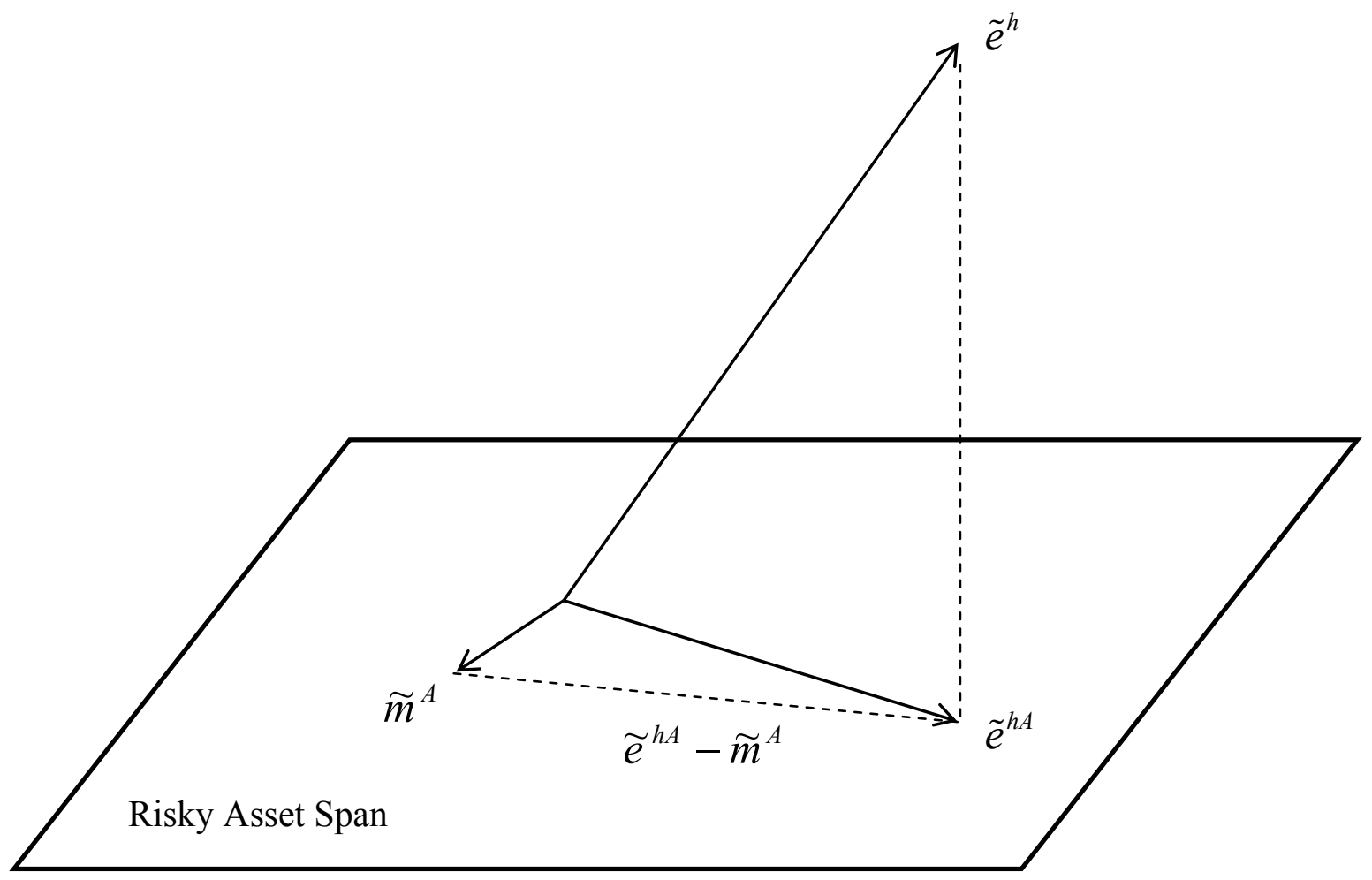

Figure 1: Geometry of the Entry Condition. An agent with random income $\widetilde{e}^{h}$ participates in risky asset markets if the distance between the tradable component of her endowment $\widetilde{e}^{h A}$ and the tradable security $\widetilde{m}^{A}$ is larger than $\sqrt{2 \kappa R / \gamma}$ 


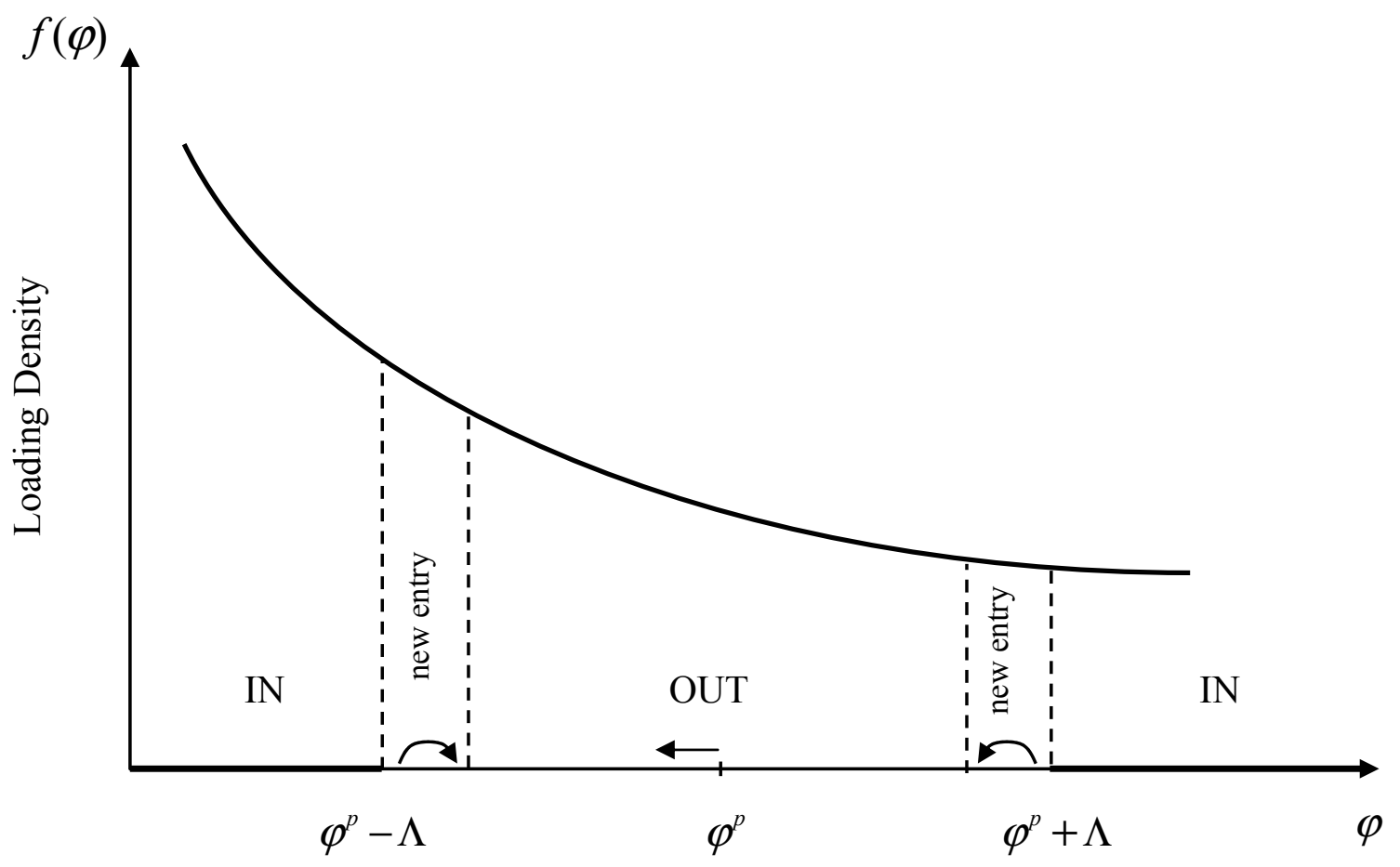

Factor Loading

Figure 2: Effect on Participation of a Decrease in $\Lambda$. Financial innovation, either in the form of improved spanning or lower transaction costs, reduces the nonparticipation parameter $\Lambda=\sqrt{2 \kappa R /(\alpha \gamma)}$. When the cross-sectional distributional of risk is skewed to the left, a majority of entrants have low risk exposure. As a result, the participants' average loading $\varphi^{p}$ and the risk premium fall. 


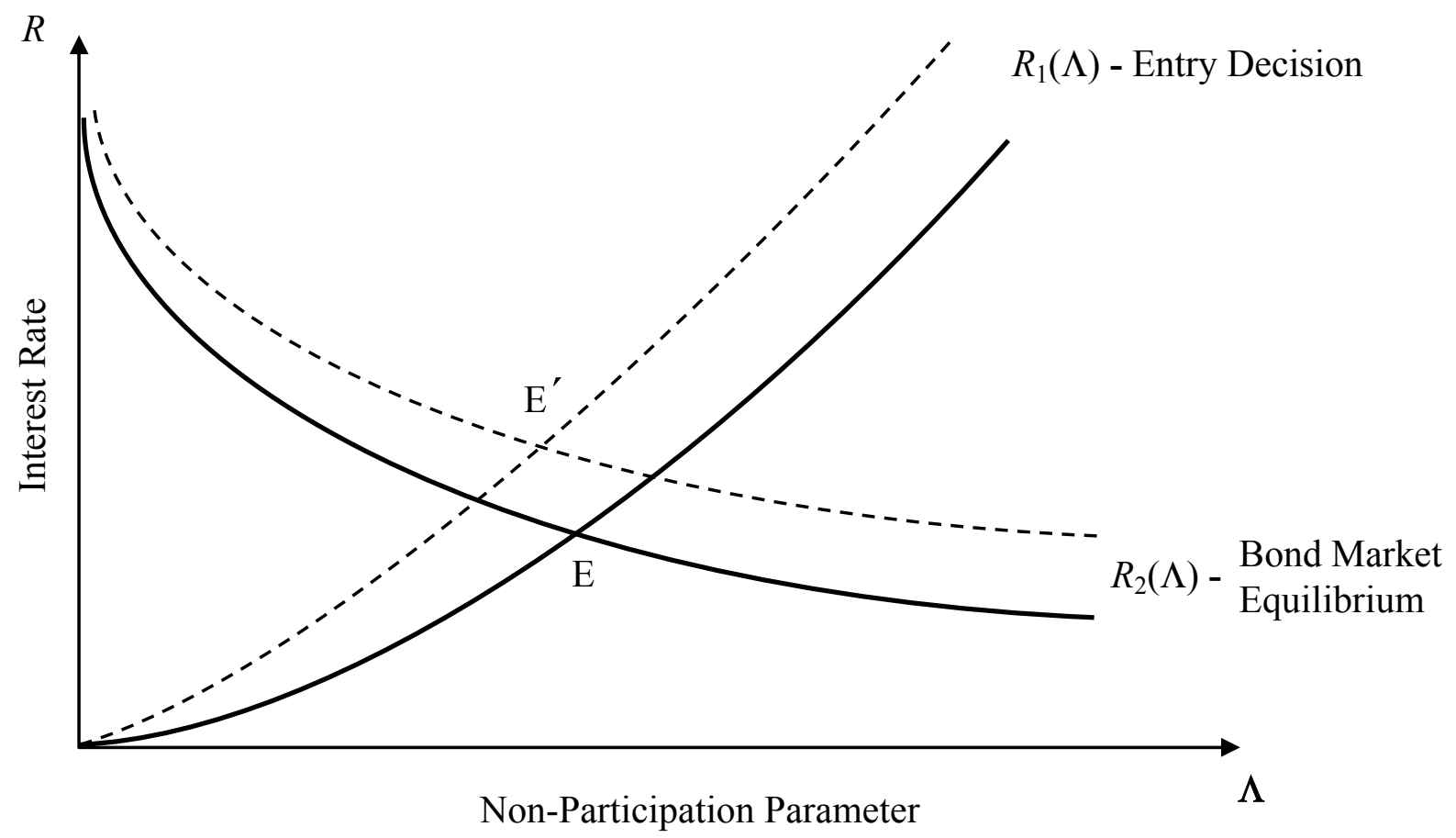

Figure 3: Equilibrium of the One-Factor Economy. The equilibrium $E$ of the endogenous participation economy is determined by the intersection of the curves $R_{1}(\Lambda)$ and $R_{2}(\Lambda)$, which respectively express the entry condition and the equilibrium of the bond market. The introduction of a new asset pushes up both curves. In the new equilibrium $E^{\prime}$, the interest rate $R$ is higher and the shift in the non-participation parameter $\Lambda$ is generally ambiguous. 


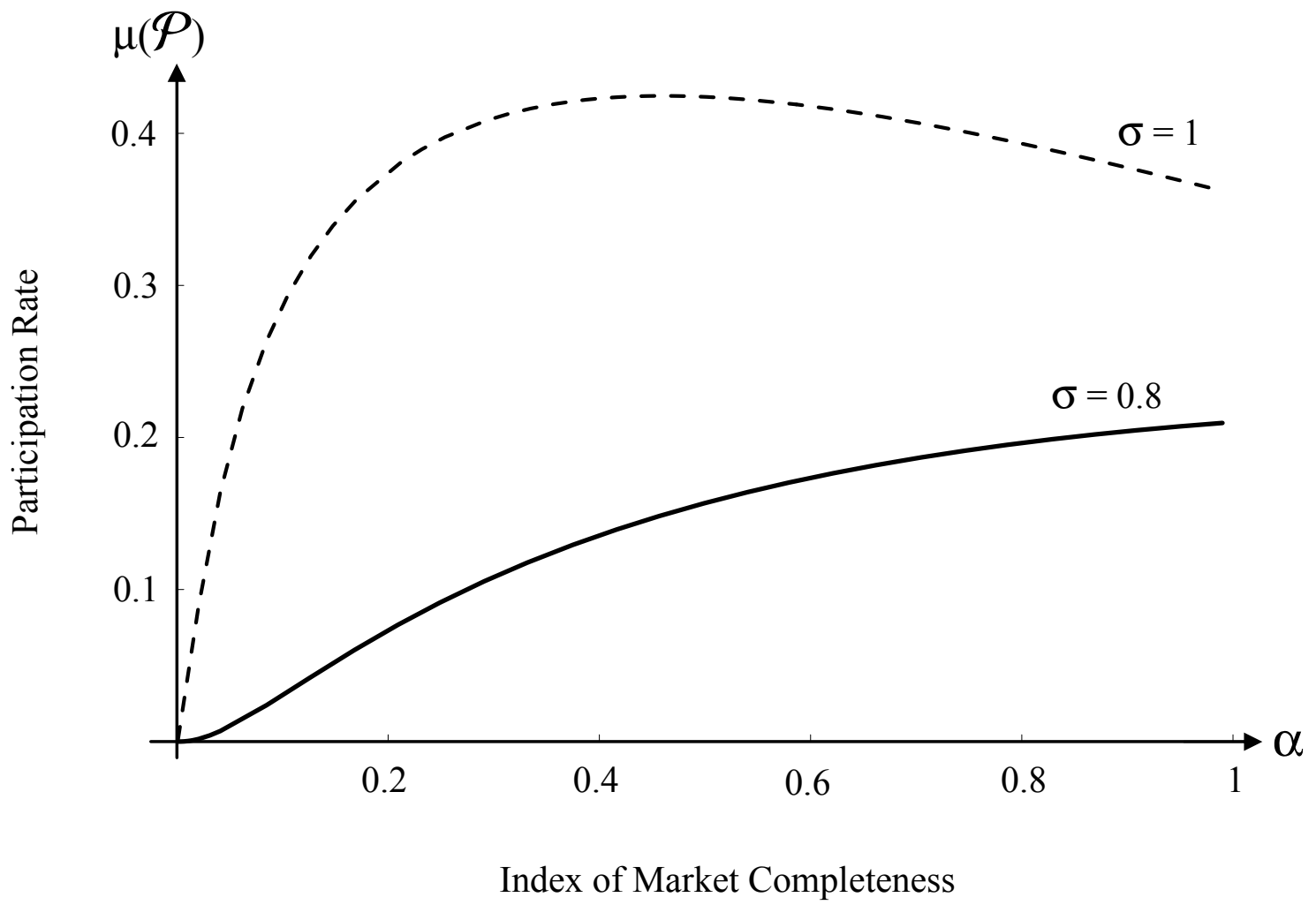

Figure 4: Effect of Financial Innovation on Market Participation. We consider a one-factor economy with a lognormal cross-sectional distribution or risk: $\ln (\varphi) \sim$ $\mathcal{N}\left(0, \sigma^{2}\right)$. The solid curve corresponds to $\sigma=0.8$, and the dashed curve to $\sigma=1$. The other parameters of the economy are: $\gamma=\chi=1, \kappa=1$ and $\beta=1$. When the completeness index $\alpha$ increases from 0 to 1 , participation monotonically increases in one economy $(\sigma=0.8)$, and reaches a maximum for an intermediate value of $\alpha$ in the the other $(\sigma=1)$. Non-monotonicity arises from the larger heterogeneity of individual incomes in the second economy. Financial innovation then induces a sharp reduction in the precautionary supply of savings, which leads to a strong increase of the interest rate and the exit of some participants. 
A. Equity Premium (\%)

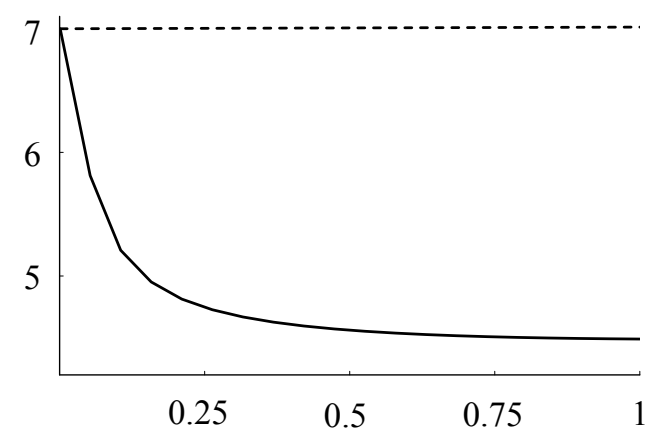

Completeness Index $\alpha_{2}$

C. Volatility of Stock Return (\%)

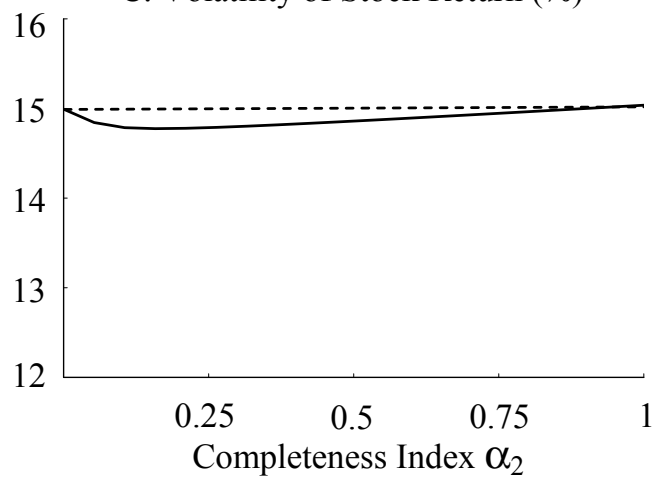

B. Interest Rate (\%)

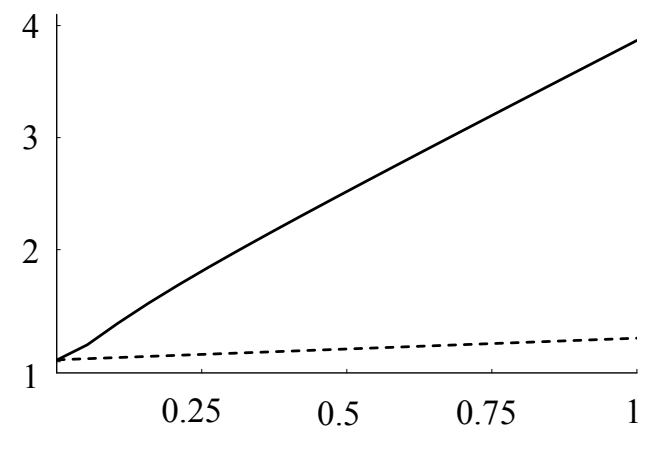

Completeness Index $\alpha_{2}$

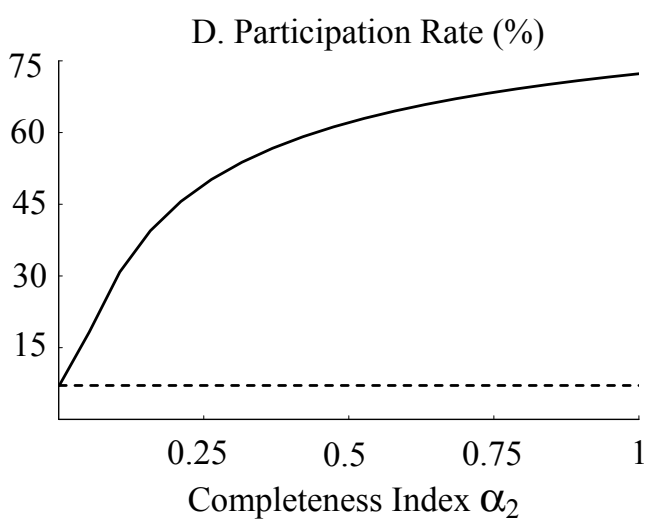

Figure 5: Comparative Statics in a Two-Factor Economy. Individual labor income is exposed to an aggregate shock $\widetilde{\mathcal{E}}_{1}$ and an idiosyncratic risk $\widetilde{\mathcal{E}}_{2}$. The aggregate shock is partially insurable $\left(\alpha_{1}=0.5\right)$. The idiosyncratic risk is uncorrelated to existing assets when $\alpha_{2}=0$ and is fully insurable when $\alpha_{2}=1$. The other parameters are $\beta=0.96, \gamma=$ $10, \chi=0.5, \kappa=0.8 \%, \sigma_{1}=4 \%$ and $\sigma_{2}=10 \%$. The solid lines illustrate equilibrium in the endogenous participation economy as the coefficient $\alpha_{2}$ varies from 0 to 1 . The dashed lines are plotted assuming a fixed set of traders. For comparison purposes, the participation sets in both economies coincide when $\alpha_{2}=0$. The effects of innovation on the risk premium is substantially stronger under endogenous entry. 


\section{A. Intermediate Set}

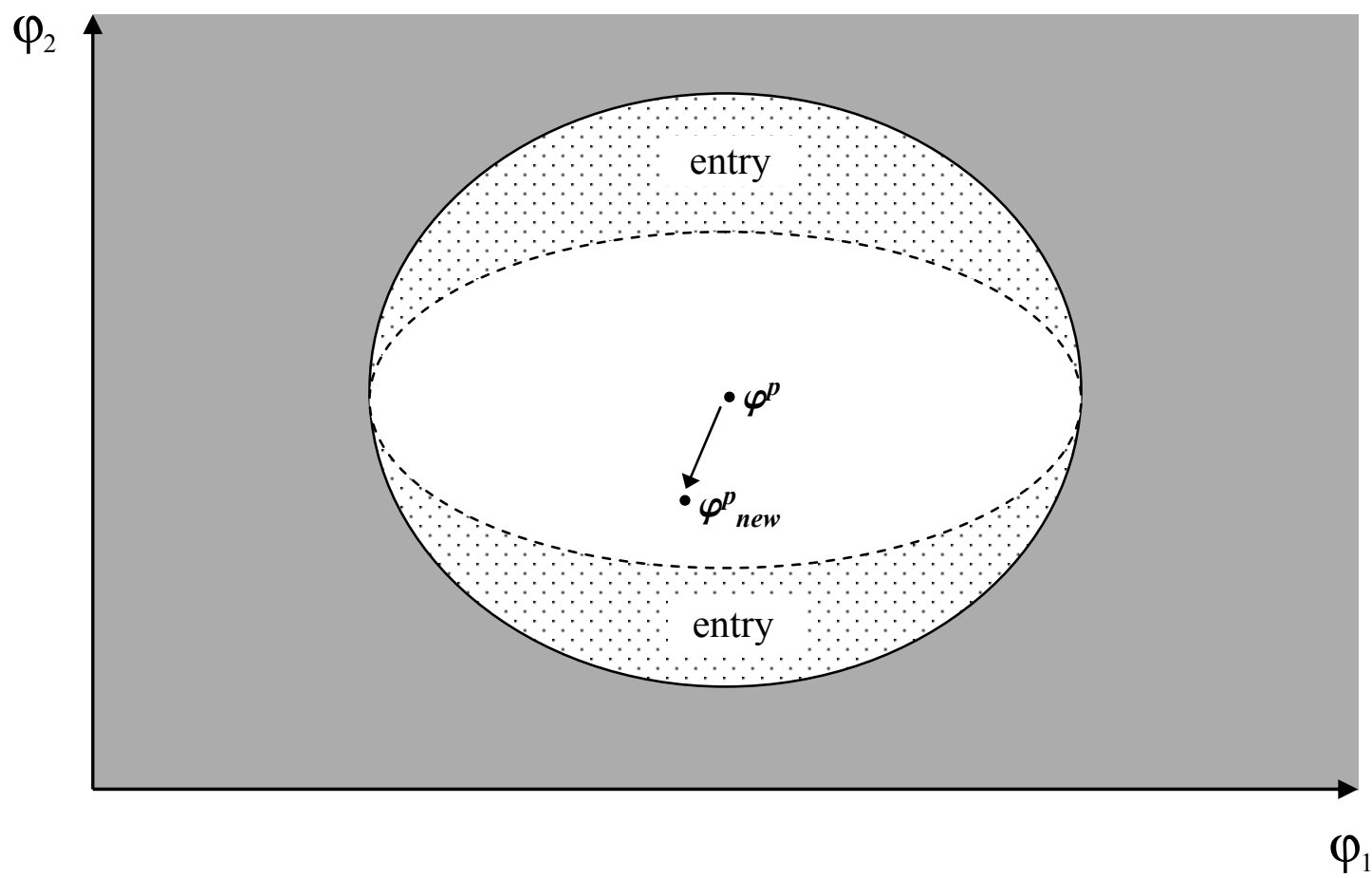

B. New Participation Set

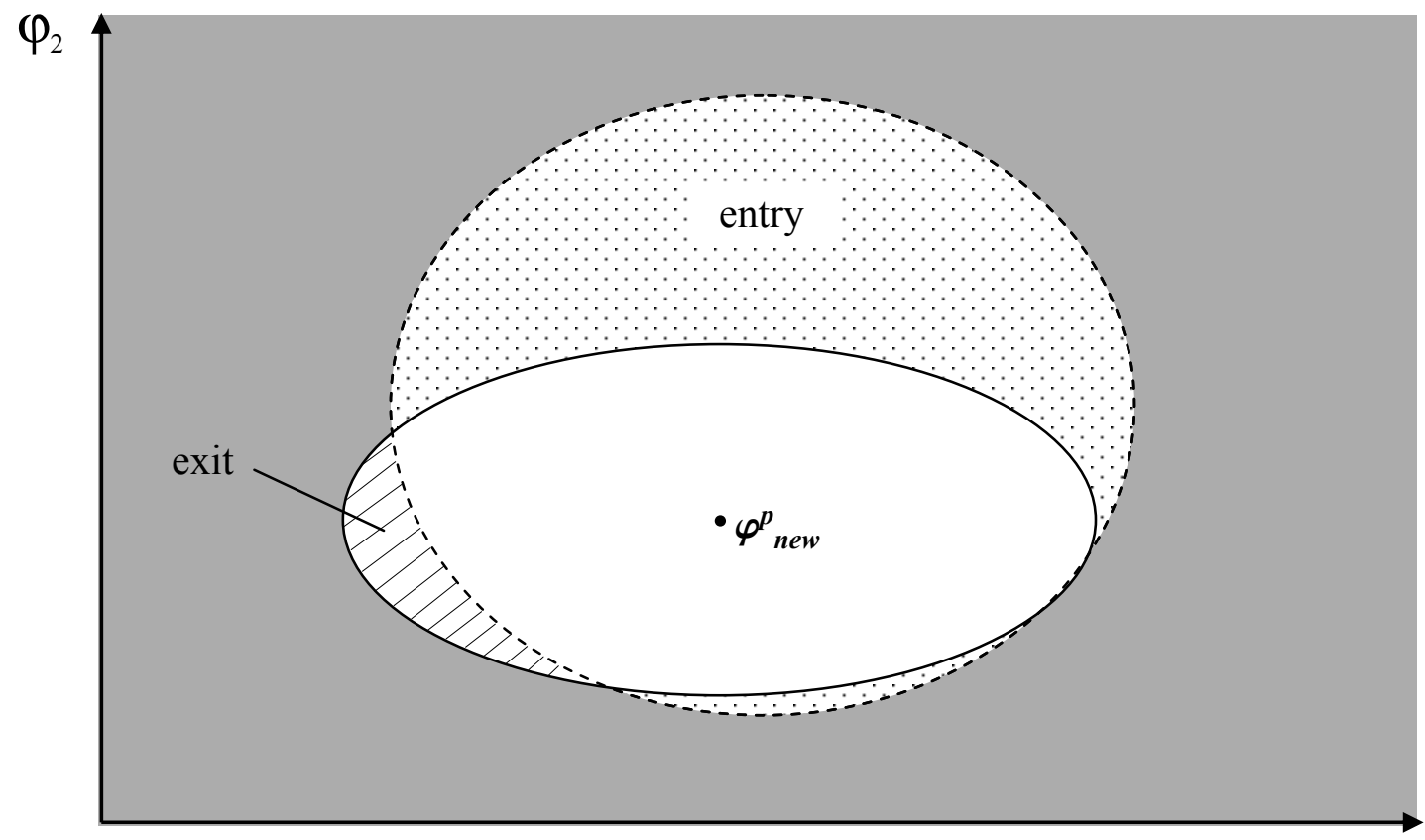

$\varphi_{1}$

Figure 6: Effect on Participation of an Increase in $\alpha_{2}$. Initial participants are located outside the large ellipse of Panel A. When $\alpha_{2}$ increases, the boundary shrinks vertically (small ellipse), and new entrants move the average loadings from $\varphi^{p}$ to $\varphi^{p}{ }_{n e w}$. The new participation set is delimited by the small ellipse of Panel B. The dotted area contains the new entrants, and the dashed area the agents who left the markets. 


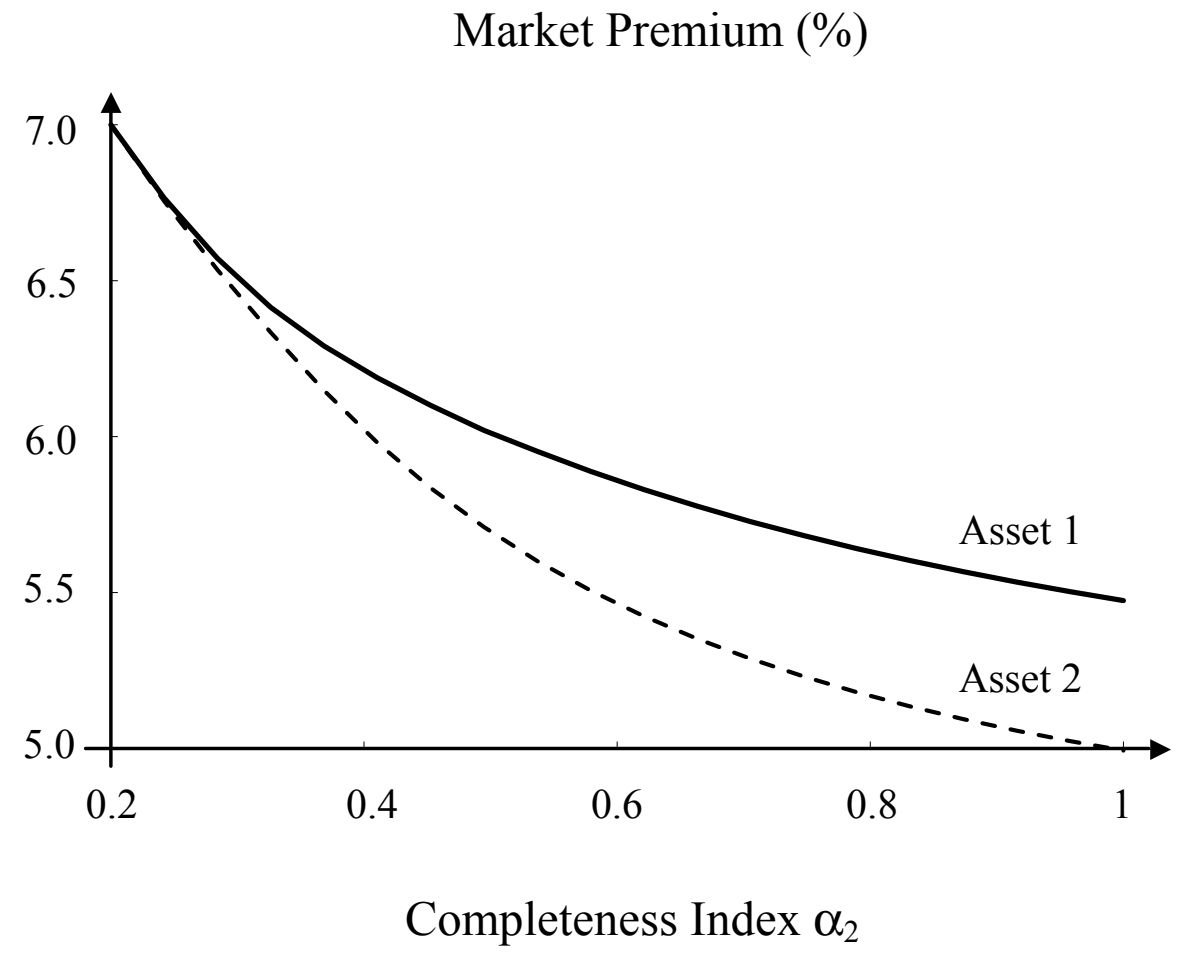

Figure 7: Differential Effects of Financial Innovation. The cross-sectional loading density is the product: $f\left(\varphi_{1}, \varphi_{2}\right)=g\left(\varphi_{1}\right) g\left(\varphi_{2}\right)$, where $g$ is the density of a log-normal variable $Z: \ln Z \sim \mathcal{N}(-3.5,1)$. Note that exposures to the aggregate and idiosyncratic risks are independent in the population. The other parameters of the economy are: $\gamma=$ $10, \chi=0.5, \beta=0.96$ and $\kappa=0.8 \%$. The initial economy has completeness indexes $\alpha_{1}=$ $\alpha_{2}=0.2$, and contains two fixed assets $\widetilde{a}_{\ell}=x+\widetilde{\varepsilon}_{\ell}^{A} \quad(\ell=1,2)$. As $\alpha_{2}$ increases from 0.2 to 1 , both risk premia fall. The effect is stronger for the second asset, which is in the sector experiencing financial innovation. 


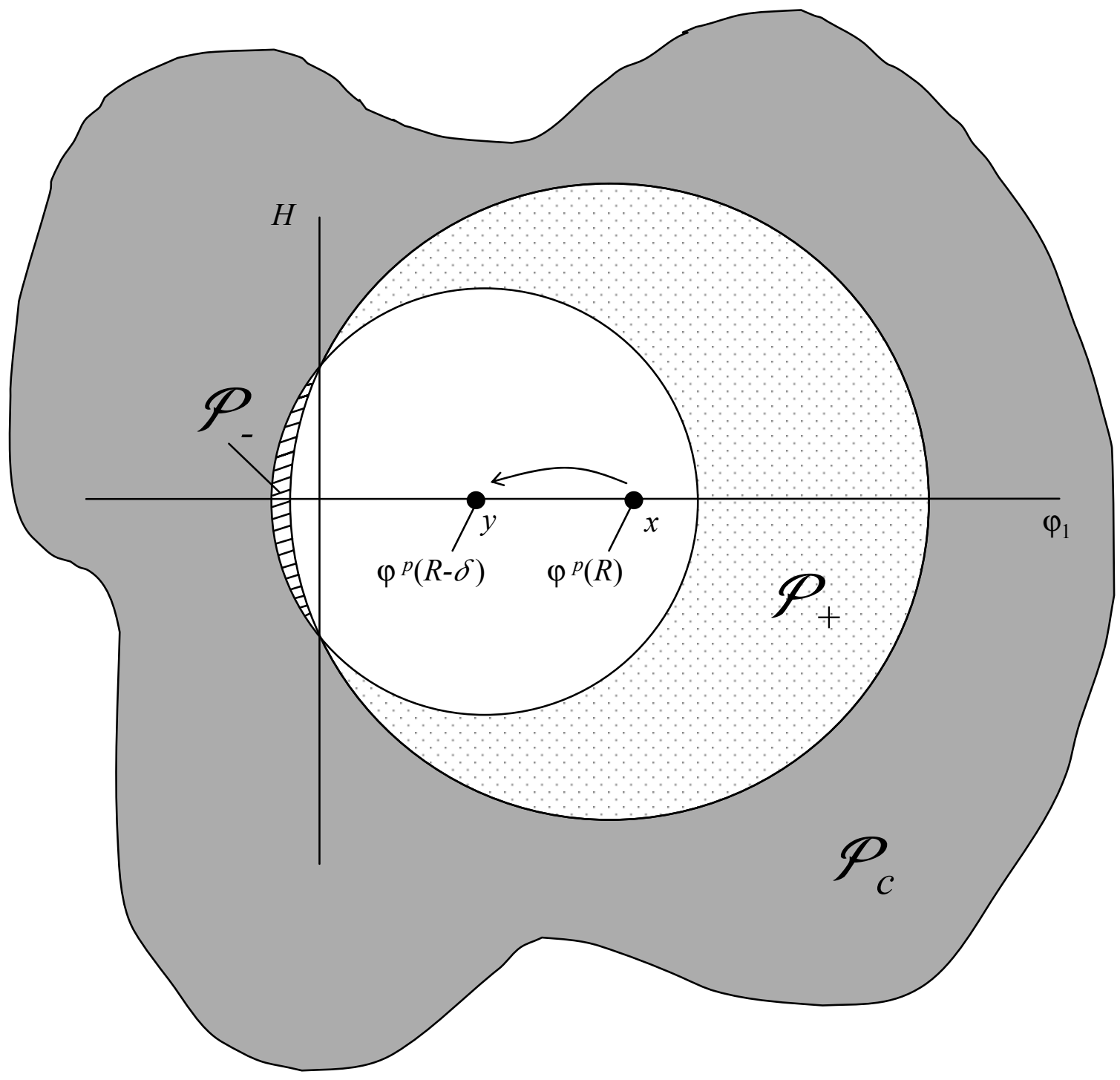

Figure 8: Geometry of the Participation Sets. When the interest rate falls from $R$ to $R-\delta$, the average loading moves from $\varphi^{p}(R)$ to $\varphi^{p}(R-\delta)$. Agents in $\mathcal{P}_{+}$enter the market,

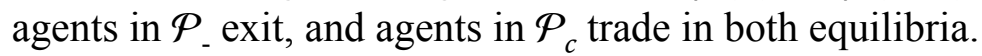

